\title{
Die politische Stellung der Juden im mittelalterlichen Süditalien und die Massenkonversion der Juden im Königreich Neapel im Jahr 1292*
}

\author{
Benjamin Scheller
}

Fragt man nach der Stellung der Juden im späten Mittelalter und insbesondere nach ihrer Mission, dann verdient das spätmittelalterliche Königreich Neapel ein besonderes Interesse. Denn hier war es 1292 zur ersten ,spontanen' Massenkonversion von Juden in der europäischen Geschichte des Mittelalters gekommen, ein Ereignis, das sich in ähnlicher Weise nur noch einmal wiederholte, fast genau 100 Jahre später, als 1391 auf der iberischen Halbinsel ein erheblicher Teil der Juden unter Zwang die Taufe nahm. ${ }^{1}$ Und wie dort hatte dies nicht die Folge, dass die getauften Juden und ihre Nachkommen samt und sonders in die christliche Mehrheitsgesellschaft integriert worden wären. Als neofiti, christiani novi bzw. christiani novelli markierte man die konvertierten Juden und ihre Nachkommen im Königreich Neapel vielerorts auch noch nach Generationen als Neuankömmlinge, wörtlich ,neu Gepflanzte" unter den Christen. Die Geschichte der süditalienischen Neofiti, deren Spuren sich verlieren, nachdem die neue spanische Vizeregierung 1507 die Vertreibung von Juden und non boni

* Eine erste Fassung des Manuskripts las Prof. Dr. David Nirenberg (Baltimore), dem ich für Anregungen und Kritik ebenso danken möchte wie den Teilnehmern der Göttinger Akademietagung 2005, der Lehrstuhlcolloquia von Herrn Prof. Dr. Michael Borgolte (Berlin) und Herrn Prof. Dr. Wolfgang Huschner (Leipzig) und den Zuhörern eines Vortrages an der Hochschule für jüdische Studien (Heidelberg), den ich auf Einladung von Herrn Prof. Dr. Johannes Heil halten durfte. Herrn Prof. Dr. Hubert Houben (Lecce) sowie Herrn Dr. Stefano Palmieri (Neapel) möchte ich für vielfältige Hilfen bei den Recherchen in Neapel danken, der Fritz-Thyssen-Stiftung für die großzügige finanzielle Unterstützung durch die Gewährung eines Reisestipendiums.

1 Vgl. hierzu zuletzt den Überblick von David M. Gituitz: Secrecy and Deceit: The Religion of the Crypto-Jews. Philadelphia 1996, v.a. S. 3-34; Luwig Vones, Vom Pogrom zur Vertreibung. Die Entwicklung des jüdisch-christlichen Verhältnisses in den Kronen Kastilien und Aragón con 1391 bis 1492, in: Johannes Helmrath/Heribert Müller (Hrsg.), Studien zum 15. Jahrhundert. Fschr. Erich Meuthen. Bd. 2. München 1994, S. 927-953; Angus McKay: Popular Movements and Pogroms in Fifteenth-Century Castille, in: Past and Present 66, 1972, S. 33-67. 
christiani aus dem festländischen Süditalien befohlen hatte, ist noch weitgehend ungeschrieben. $^{2}$

Die massenhaften Übertritte von Juden zum Christentum, die am Beginn dieser Geschichte standen, waren allerdings weniger das Resultat genuiner Missionsbemühungen, versteht man diese als systematische Überzeugungsarbeit, auch wenn solche in Einzelfällen belegt ist. Entscheidend jedoch war weniger Persuasion als vielmehr Repression. Denn die Massenkonversion von 1292 war vor allem Folge der ersten systematischen Judenverfolgung durch die Inquisiton in der Geschichte und damit auch in dieser Hinsicht singulär. ${ }^{3}$

Diese systematische Judenverfolgung war sicherlich die Folge einer neuen Wahrnehmung der Juden bzw. eines neuen Diskurses über den Ort der Juden in der christlichen Gesellschaft, der sich seit dem 12. Jahrhundert entwickelt und sich im 13. Jahrhundert radikalisiert hatte. Die Juden galten nun immer weniger als lebendes Zeugnis der Passion Jesu Christi, sondern zusehends als Bedrohung für die Christenheit. Die Aufgabe der Kirche wurde deshalb immer weniger darin gesehen, Toleranz gegenüber den Juden zu üben, sondern sie daran zu hindern, ihren vermeintlich schädlichen Einfluss auf die Christen ausüben zu können. Jeremy Cohen hat gezeigt, dass die Bettelorden bei der Ausformulierung dieses Diskurses eine zentrale Rolle gespielt haben und hat deshalb von mendikantischem Antisemtismus gesprochen. ${ }^{4}$ Von entscheidender Bedeutung war jedoch vor allem, dass sich dieser theologische Diskurs mit jenem juristischen Diskurs der Kanonistik verband, der bereits seit dem späten 12. Jahrhundert versucht hatte, Ansprüche der Kirche, Juden vor ihr Gericht zu ziehen, $\mathrm{zu}$ fundieren. ${ }^{5}$

Man hat zu Recht betont, dass Funktion und der Effekt von Diskursen örtlich und zeitlich variieren und von ihrem sozialen Kontext und den dort

2 Vgl. aber: Vito Vitale: Un Particolare ignorato di Storia pugliese: Neofiti e Mercanti, in: Studi di Storia napoletana in Onore di Michelangelo Schipa. Napoli 1926, S. $233-$ 246.

3 Keinerlei Erwähnung findet dies bei KenNeth Stow: Ebrei e Inquisitori 1250-1350, in: Michele Luzzati (Ed.): L'Inquisizione e gli Ebrei in Italia. Bari 1994, S. 3-18; Ders.: Papi, Chiesa e Ebrei fino alla Inquisizione Romana, in: Le Inquisizioni Christiane e gli Ebrei. (Atti dei Convegni Lincei, Bd. 191.) Roma 2003, S. 33-49; zur Inquisition im Königreich Neapel vgl. Luigi Amabile, Il santo officio della inquisizione in napoli. Bd 1. Città di Castello 1892 (Ndr. 1987).

4 Jeremy Cohen: The Friars and the Jews. The Evolution of medieval Anti-Judaism. Itahaca 1982, S. 76-89; vgl. aber Robert Chazan: Daggers of Faith. ThirteenthCentury Christian Missionizing and Jewish Response. Berkeley/London 1989, v.a. S. $170-177$.

5 Walter Pakter: Medieval Canon Law and the Jews. (Abhandlungen zur rechtswissenschaftlichen Grundlagenforschung, Bd. 68.) Ebelsbach 1988, S. 40. 
vorhandenen Konflikten abhängen. ${ }^{6}$ Dass der damals noch relativ neue, mendikantische Antisemtismus im Königreich Neapel am Ende des 13. Jahrhunderts zu einer systematischen Verfolgung der Juden und letztendlich zu deren massenhafter Konversion führen konnte, hatte deshalb viel zu tun mit der politischen Stellung, die die Juden im Mittelalter auf dem süditalienischen Festland innehatten, und mit den mit ihr verbundenen Konflikten. Und es ist genau jene Wechselbeziehung zwischen dem Versuch, die Juden zum Christentum zu bekehren, und der politischen Stellung der Juden im Königreich Neapel am Ende des 13. Jahrhunderts, um die es hier gehen soll.

Zunächst sollen kurz Zeit, Ort und Ausmaß der Übertritte von Juden im Königreich Neapel am Ende des 13. Jahrhunderts skizziert werden. Danach soll die Logik herausgearbeitet werden, der die Verfolgung der Juden durch die Inquisition folgte, und das Verhältnis von Monarchie und Inquisitoren. In einem dritten und letzten Schritt wird es dann endlich um die besondere politische Stellung der Juden im mittelalterlichen Süditalien gehen, um so deutlich zu machen, dass diese ein wesentlicher Faktor war, um die Unterstützung der Monarchie für die Inquisitoren zu erklären, eine Unterstützung die für den Erfolg der inquisitorischen Bemühungen zentral war. Dies wird in Form einer Rückblende geschehen, die bis in die Zeit Friedrichs II. zurückgreift. Zuvor jedoch noch einige Bemerkungen zur politisch-geographischen Terminologie und zu Forschungsstand und Quellenlage.

Der Begriff, ,Königreich Neapel' erscheint erstmals Mitte des 14. Jahrhunderts in den Quellen und kam in der Kanzlei der Könige, die in Neapel residierten, erst am Beginn des 16. Jahrhunderts auf. Bis dahin titulierten sie sich weiterhin als rex Sicilie. Dennoch ist es sinnvoll für die Zeit nach der sizilischen Vesper 1282 für den festländischen Teil des ehemaligen Königreichs Sizilien vom Königreich Neapel zu sprechen, um Irritationen zu vermeiden. ${ }^{7}$

Die Massenkonversion der Juden im Königreich Neapel ist von der Forschung nicht gänzlich unbeachtet geblieben. Sie findet in allen Handbüchern und Überblicksdarstellungen zur Geschichte der Juden in Süditalien im Mittelalter Erwähnung. ${ }^{8}$ Jeremy Cohen widmete ihr im Rahmen seiner Untersu-

6 David Nirenberg: Communities of Violence. Persecution of Minorities in the Middle Ages. Princeton, New Jersey 1996, S. 124.

7 Hierzu Andreas Kiesewetter: Die Anfänge der Regierung Karls II. von Anjou (12781295). Das Königreich Neapel, die Grafschaft Provence und der Mittemeerraum zu Ausgang des 13. Jahrhunderts. (Historische Studien, Bd. 451.) Husum 1999, S. 13 f.

8 David Abulafia: Il Mezzogiorno peninsulare dai Bizantini all'Espulsione, in: Corrado Vivanti (Ed.), Storia d' Italia, Annali 11/1. Dall'Alto Medioevo all'Età dei Ghetti. Torino 1996, S. 5-44, hier S. 19-24; vgl. Ders.: L'Età Sveva Angioina, in: Cosimo Damiano Fonseca/Michele Luzzati/Giuliano Tamani/Cesare Colafemmina (Eds.): L'Ebraismo dell'Italia Meridionale peninsulare dalle Origini all 1541. Società, Economia, Cultura. Bari 1996, S. 65-78, hier S. 68-73; Atтilio Milano: Storia degli 
chung des mendikantischen Antisemitismus ebenso einige Seiten wie Shlomo Simonsohn in seinem Überblick über das Verhältnis des Papsttums zu den Juden. Auch Joseph Shatzmiller und Andreas Kiesewetter haben sich kurz mit ihr befasst. ${ }^{9}$ Bereits 1913 hatte Umberto Cassuto ihr unter dem bezeichnenden Titel un ignoto capitolo di storica ebraica eine kurze Abhandlung gewidmet. ${ }^{10}$ Nach Cassuto kamen jedoch nur noch Joshua Starr 1946 und unlängst David Abulafia eigens auf die Massenkonversion der süditalienischen Juden zurück. ${ }^{11}$ Eine eingehende Analyse der Vorgänge auf der Basis des gesamten verfügbaren Quellenmaterials fehlt jedoch.

Ein vollständiges und gleichmäßig tiefenscharfes Bild der Vorgänge, die 1292 zur Massenkonversion der Juden des regno führte, lässt sich dabei jedoch leider nicht zeichnen. Zeitgenössische Zeugnisse aus dem Umfeld der Juden selbst sind nicht überliefert. Erst über zweihundert Jahre später finden die Ereignisse von 1292 bei Samuel Usque, Salomon Ibn Verga und Joseph HaKohen Erwähnung, also bei jenen spanischen Exilanten, die man als die ,lacrimose' Schule der jüdischen Geschichtsschreibung bezeichnet. ${ }^{12}$

Nach Usque, dem Ha-Kohen mit geringfügigen Abweichungen folgt, hätten die Juden von Neapel und Trani dem König, der in einen langen und gefährlichen Krieg verwickelt gewesen sei, ihr gesamtes Vermögen zur Verfügung gestellt. Nach siegreicher Beendigung des Krieges habe der König den Juden dies in vielfältiger Weise vergolten und sie auf eine Stufe mit den Adligen des Reiches gestellt, worauf sie so hochmütig geworden wären, dass sie ihre Treue

Ebrei in Italia. Torino 1963, S. 99-104; CесіL Rотн: The History of the Jews of Italy. Philadelphia 1946, S. 100-102; Nicola Ferorelli: Gli Ebrei nell'Italia meridionale. Torino 1915 (Ndr. Napoli 1990), S. 53-58.

9 Cohen, Friars and the Jews (wie Anm. 4), S. 85-89; Shlomo Simonsohn: The Apostolic See and the Jews. Bd. 7. Toronto 1991, S. 350 f.; Joseph Shatzmiller : Les Angevins et les Juifs de leurs États, in: L'État Angevin. Pouvoir, Culture et Société entre xiii $^{\mathrm{e}}$ et xiv ${ }^{\mathrm{e}}$ Siècle. (Collection de l'École Française de Rome, Bd. 245.) Rom 1998, S. 289-300, hier S. 292 f.; Kiesewetter, Anfänge der Regierung Karls II. (wie Anm. 7), S. 516-518.

10 Umberto Cassuto: Un ignoto Capitolo di Storia giudaica, in: Judaica. Fschr. Hermann Cohen 70. Berlin 1912, S. 389-404.

11 Joshua Starr: The Mass Conversions of Jews in Southern Italy (1290-93), in: Speculum 21, 1946, S. 139-152; David Abulafia: Monarchs and Minorities in the christian western Mediterranean around 1300: Luceras and it's Analogues, in: Sсотт L. Waugh/Peter D. Diehl (Eds.): Christendom and it's Discontents: Exclusion, Persecution and Rebellion 1000-1500. Cambridge 1996, S. 234-260, hier S. 251-256; vgl. Ders.: Die Verfolgung der Juden in Süditalien und Sizilien (1290-1541), in: Friedhelm Burgard/Alfred Haverkamp/Gerd Mentgen (Hrsg.): Judenvertreibungen in Mittelalter und früher Neuzeit. (Forschungen zur Geschichte der Juden, Abt. A, Bd. 9.) Hannover 1999, S. 99-118, hier S. $102 \mathrm{f}$.

12 Cassuto, Un ignoto Capitolo (wie Anm. 10), S. 396-398; zur lacrimosen Schule vgl. Yosef Hayim Yerushalmi: Zachor: Erinere Dich! Jüdische Geschichte und jüdisches Gedächtnis. Berlin 1988, S. 67-78. 
gegenüber Gott vergessen hätten. Diesem Hochmut folgte ein tiefer Fall. Als der König starb, habe er seinen Sohn aufgefordert, sich den Juden gegenüber in gleicher Weise großzügig und wohlgesinnt zu erweisen. Darauf habe der neue König dann den Entschluss gefasst, die größte Wohltat, die er den Juden seines Reichs erweisen könne, bestünde darin, sie zum christlichen Glauben zu bekehren, um sie so vor der ewigen Verdammung zu bewahren. Die Juden des Königreichs hätten dem König daraufhin mitgeteilt, sie seien zur Konversion bereit unter der Voraussetzung, dass sie danach Eheverbindungen mit den Großen des Reichs eingehen könnten, in der Hoffnung der König würde dies ablehnen und von seinem Ansinnen absehen, sie zu bekehren. Stattdessen hätte der König ihre Bedingung jedoch akzeptiert und einen Befehl ausgegeben, dass alle Juden seines Reichs die Wahl zwischen Taufe oder Tod hätten. Daraufhin hätten die Juden, bis auf einige Ausnahmen aus Angst vor dem Tod ihrem Glauben abgeschworen. ${ }^{13}$

Ibn Verga zufolge war die Massenkonversion Folge der Hinterlist eines Priesters in der Stadt Trani. Nach einem Streit mit einem Juden habe er nachts heimlich ein Kruzifix in den Abfällen des Juden deponiert und dann am nächsten Morgen verkündet, er habe im Traum gesehen, dass die Juden das Kreuz in den Abfall würfen. Daraufhin seien die Christen der Stadt ausgezogen, um nachzuforschen und hätten prompt das Kruzifix in den Abfällen des Juden gefunden. Dem daraufhin aufbrandenden Volkszorn hätten sich die Richter zunächst noch entgegengestellt. Als sie jedoch sahen, dass sie ihm nicht widerstehen konnten, hätten sie den Juden geraten, sich zu retten, indem sie die Taufe nehmen. ${ }^{14}$

Usques und Ibn-Vergas Erzählungen verwenden Informationen, die teilweise unmittelbar oder mittelbar auf eine gemeinsame Quelle zurückgehen, der sie die Namensformen der erwähnten Städte und die - falsche - Jahreszahl (1240/5000) entnommen haben, eine „wenig individuelle(.) Sammlung von verschiedenartigsten Berichten und Notizen, die, häufig umgeformt, durch mehrere Hände gegangen sind" und die letztlich auf mündliche Überlieferung zurückgehen. ${ }^{15}$ Diese kombinieren sie wohl mit mündlicher Überlieferung, aus der sie schöpfen konnten, als sie sich 1507 (Ibn-Verga) bzw. 1531 (Usque) in

13 Samuel Usque: Consolation for the Tribulations of Israel (Consolaçam as Tribulaçoens de Israel), trans. From the Portuguese by. Martin A. Cohen. Philadelphia 1977, S. $178-180$.

14 Salomo Aben Verga (Ibn Verga): Das Buch Schevet Jehuda, aus dem Hebr. ins Deutsche übertr. v. Meir Wiener. Bd. 2. Hannover 1856, S. 133 f.; vgl. Cassuto, Un ignoto Capitolo (wie Anm. 10), S. 396.

15 Fritz BaER: Untersuchungen über Quellen und Komposition des Schebet Jehuda. (Veröffentlichungen der Akademie für die Wissenschaft des Judentums, Historische Sektion, Bd. 2.) Berlin 1923, S. 37; Cassuto, Un ignoto Capitolo (wie Anm. 10), S. 400 . 
Neapel aufhielten. ${ }^{16}$ Zumindest Ibn-Verga berichtet, dass die Quelle seines Wissens zum Teil Erzählungen der Alten seien. ${ }^{17}$ Außerdem sind die Erzählungen Usques und Ibn-Vergas stark durch das jeweilige didaktische Ziel ihrer Schriften bestimmt. Das in ihnen repräsentierte Erinnerungswissen hatte also sowohl den „primären als auch den sekundären Verformungsfaktoren des Gedächtnisses" unterlegen. ${ }^{18}$

Das gleiche gilt für die Repräsentation der Massenkonversion von 1292 in einer Predigt, die der Dominikaner Giordano da Pisa 1304 in Florenz hielt, auch wenn hier nur etwas über zehn Jahre zwischen Ereignis und Erzählung liegen. Giordanos Predigtexempel basiert wahrscheinlich auf Erzählungen neapolitanischer Dominikaner. Ihm zufolge sei es König Karl von Neapel 10 oder 15 Jahre zuvor zu Ohren gekommen, dass die Juden seines Reichs Ritualmorde begingen. Auf den Rat eines frate Bartolomeo, chera ministro habe er darauf die Juden Apuliens vor die Wahl Tod oder Taufe gestellt, worauf diese samt und sonders konvertiert wären. ${ }^{19}$

Ein gänzlich anderes Bild als diese späteren narrativen Repräsentationen zeichnen die unmittelbar zeitgenössischen Zeugnisse. Diese bestehen vor allem aus Mandaten der königlichen Kanzlei. Die erhaltenen Kanzleiregister der sizilischen bzw. neapolitanischen Könige aus dem Haus Anjou sind jedoch bekanntlich 1943 von deutschen Truppen zerstört worden. ${ }^{20}$ Jeder Versuch, Licht auf die Massenkonversion von $1292 \mathrm{zu}$ werfen, muss sich daher mit den Splittern begnügnen, die noch erhalten sind, entweder in älteren Editionen aus den Registern, in Empfängerüberlieferung und in älteren Abschriften, die heute eine Grundlage für die Rekonstruktion der verlorenen Register bilden. ${ }^{21}$ Allerdings sind diese durchaus ausreichend, um Ort, Zeit und Ausmaß der massenhaften Übertritte von Juden im Königreich Neapel zu bestimmen und die

16 Usque, Consolation, trans. Cohen (wie Anm. 13), S. 13; Baer, Untersuchungen über Quellen und Komposition (wie Anm. 15), S. 75-78.

17 Aben Verga (Ibn Verga): Schevet Jehuda, übertr. v. Wiener (wie Anm. 14), S. 133; vgl. Cassuto, Un ignoto Capitolo (wie Anm. 10), S. 397.

18 Dies nach Johannes Fried: Der Schleier der Erinnerung. Grundzüge einer historischen Memorik. München 2004, S. 49-56.

19 Carlo Delcorno: Giordano da Pisa e l'antica predicazione volgare. Firenze 1975, S. $25,284$.

20 Hierzu zuletzt Lutz Klinkhammer: Die Abteilung „Kunstschutz“ der deutschen Militärverwaltung in Italien 1943-1945, in: QFIAB 72, 1992, S. 483-549; ARNOLD Esch/ Andreas Kiesewetter: Süditalien unter den ersten Angiovinen: Abschriften aus den verlorenen Anjou-Registern im Nachlass Eduard Sthamer, in: QUFIAB 74, 1994, S. 646-663; Hubert Houben: Neue Quellen zur Geschichte der Juden und Sarazenen im Königreich Sizilien (1275-1280), in: QFIAB 74, 1994, S. 335-359, 335.

21 I registri della cancelleria angioina ricostruiti, ed. RiCCARdo FilANGERI et al. Bd. 1-47. Napoli 1950-2003 (RCA). 
grundlegenden Handlungsmuster und Strukturen zu erkennen, die der Verfolgung der Juden und ihren massenhaften Übertritten zugrundelagen.

\section{Die Massenkonversion von 1292}

Es kann als gesichert gelten, dass in den frühen 90er Jahren des 13. Jahrhunderts die Judengemeinden von mehr als 21 Städten des Königreichs Neapel zum Christentum übertraten. Diese lagen vor allem in Apulien und Kampanien; in der Basilikata ist nur für einen Ort, Melfi, belegt, dass dort Juden konvertiert wären. Die bedeutenden Judengemeinden Kalabriens dagegen wurden von den Übertritten offensichtlich nicht erfasst. Die Hauptwelle der Übertritte fiel dabei allem Anschein nach in das Jahr 1292. Zu diesem Jahr vermerkte ein unbekannter zeitgenössischer Kleriker des Domkapitels von Bovino als Randnotiz in einer Bibelhandschrift, dass durch die Brüder Guilelmus de Tocco, Bartholomeus d'Aquila und Iohannes de Sancto Martino vom Orden des hl. Dominicus, Inquisitoren in Apulien, eine große Zahl von Juden in verschiedenen Städten und Orten ad sacrosanctam religionem Romane Ecclesie bekehrt worden seien. ${ }^{22}$

Auch mehrere Königsmandate belegen das Wirken der erwähnten Inquisitoren und bzw. oder den Übertritt von Juden zum Christentum in diesem Jahr. ${ }^{23}$ Und auf dem Provinzialkapitel der römischen Provinz der Dominikaner in Rom wird 1292 schließlich beschlossen, dass jeder Priester des Ordens täglich eine Messe lessen sollte pro Iudeis conversis ad fidem in regno Cecilie. ${ }^{24}$

Dieser großen Welle von Konversionen waren jedoch bereits kleinere vorangegangen. Erste, einzelne Übertritte von Juden zum Christentum sind bereits für die Zeit kurz nach dem Herrschaftsantritt Karls von Anjou in Süditalien im Jahr 1266 nachgewiesen, 1267 und 1270. Weitere Nachrichten über Konversionen sind für die Jahre 1290 und 1291 belegt, doch ist es nicht unwahrscheinlich, dass es zumindest in der Zeit zwischen 1270 und 1283 ebenfalls zu Übertritten von Juden zum Christentum kam. ${ }^{25}$ Die Massenkonversion der Juden im Königreich Neapel von 1292 war also offensichtlich Kulminationspunkt eines längerfristigen Prozesses.

$\mathrm{Ob}$ es nach $1292 \mathrm{zu}$ weiteren Konversionen kam, lässt sich weniger deutlich erkennen. Auf jeden Fall ist für 1293 belegt, dass zwei spanische Dominika-

22 Marco Vatasso: Le due Bibbie di Bovino. Roma 1900, S. 39.

23 RCA (wie Anm. 21) 40, S. 72 f.; Gennaro M. Monti: Da Carlo I a Roberto d'Angio, in: Archivio Storico per le Province Napoletane (ASPN) 59, 1934, S. 158-173, hier S. 161, Anm. 12; Codice diplomatico dei saraceni di Lucera, ed. Pietro Egidi. Napoli 1917 (CDSL), Nr. 85.

24 Acta Capitulorum Provinciae Romanae (1243-1344), ed. Thomas Kaeppeli. (MOP, Bd. 20.) Romae 1941, S. 110.

25 S. hierzu u. bei Anm. 47. 
nerbrüder von Stadt zu Stadt zogen und dort contra iudeos predigten, und das auch auf Hebräisch. ${ }^{26}$ Im Jahr 1294 schließlich befreite König Karl II. konvertierte Juden in über 21 Städten auf Lebzeiten von allen Steuern und Abgaben. ${ }^{27}$

Insgesamt werden in den entsprechenden Mandaten gut 1300 erwachsene, männliche Neofiti namentlich erwähnt. Ihre Zahl reichte von gerade einmal zwei in San Severo bis zu 310 in der apulischen Hafenstadt Trani. ${ }^{28}$ Da es sich bei ihnen wohl jeweils um das steuertechnisch relevante Oberhaupt eines Haushalts handelte, muss man davon ausgehen, dass die Gesamtzahl der konvertierten Juden wesentlich höher lag, je nach angenommener Haushaltsgröße zwischen 6000 und 8000 Personen. ${ }^{29}$

Damit war bis 1294 ein erheblicher Teil der Juden Apuliens und Kampaniens zum Christentum übergetreten, auch wenn sich natürlich nicht bestimmen lässt, wie groß dieser exakt war. Zumindest berichtet ein Mandat für Salerno, dass dort die Juden „fast alle“ (universaliter fere) konvertiert wären. ${ }^{30}$ In Bari wurde nach 1292 die iudeca zunächst in ruga nova und dann in ruga neophitorum umbenannt, auch hier war offensichtlich der Großteil der Gemeinde übergetreten. ${ }^{31}$ In Neapel dagegen scheint auch nach 1292 noch eine Judengemeinde bestanden zu haben, deren Kopfzahl die der Neofiti überstieg. ${ }^{32}$ Um ihren Glauben nicht verleugnen zu müssen, scheint allerdings auch eine nicht abschätzbare Anzahl von Juden geflohen zu sein. Zumindest baten einige Juden 1294 König Karl II. um Erlaubnis, in das regno zurückkehren zu dürfen. ${ }^{33}$

Die zitierte Randnotiz aus Bovino führt die Massenkonversion von 1292 auf das Wirken dominikanischer Inquisitoren zurück. ${ }^{34}$ Und auch die urkundlichen Quellen machen deutlich, dass die Massenkonversion ein Ergebnis der Verfolgung der Juden durch die Inquisitoren war. Und obwohl die Informationen

26 Romolo Caggese: Roberto d'Angio e i suoi Tempi. Bd. 1. Firenze 1922, S. 299; Ferorelli, Gli Ebrei (wie Anm. 8), S. 54.

27 Transkriptionen der entsprechenden Urkunden mit Listen der getauften Juden in: RCA (wie Anm. 21) 47, S. 55-57 (Neapel); RCA 46, S. 85 f. (Salerno); Matteo Camera: Memorie Storico-Diplomatiche dell'Antica Città e Ducato di Amalfi. Bd. 1. Salerno 1876, S. 348 (Amalfi); Cesare Colafemmina: Ebrei e Christiani Novelli in Puglia. Le Communità minori. Bari 1991, S. 30 f. (Gravina).

28 Vgl. Ferorelli, Gli Ebrei (wie Anm. 8), S. 55; Caggese, Roberto d'Angio 1 (wie Anm. 26), S. 299.

29 Ferorelli, Gli Ebrei (wie Anm. 8), S. 55.

30 RCA (wie Anm. 21) 40, S. 72.

31 Le pergamene di San Nicola di Bari: Periodo Angioino (1266-1309), ed. Francesco NitTi de Vito (Codice diplomatico Barese [CDB]. Bd. 13.). Trani 1936. Nr. 116, Nr. 148.

32 Ferorelli, Gli Ebrei (wie Anm. 8), S. 43.

33 Ferorelli, Gli Ebrei (wie Anm. 8), S. 54.

34 S. o., S. 149. 
oftmals nicht eben reichhaltig sind, lässt sich durchaus erkennen, wie die Inquisitoren dabei vorgingen und vor allem auf welche diskursiven Ressourcen sie zurückgriffen, um die Verfolgung der Juden zu legitimieren.

\section{Die Logik der inquisitorischen Judenverfolgung}

Die inquisitorische Judenverfolgung war, wenn man so will, eine Folge der erwähnten vereinzelten Übertritte von Juden zum Christentum, die in den späten 60er Jahren des 13. Jahrhunderts einsetzten. Denn hierdurch kam ein Prozess in Gang, der sich mit den Worten Solomon Grayzels folgendermaßen beschreiben lässt: „Conversion was followed by regret, and regret by inquisition ". ${ }^{35}$ Wie es zu diesen ersten Übertritten kam, lässt sich im Einzelnen nicht nachvollziehen, es fällt allerdings auf, dass sie erst nach dem Dynastiewechsel von den Staufern zu den Anjou 1266 einsetzen. Es ist deshalb nicht unwahrscheinlich, dass die Bettelorden, die damals in das regno zurückkehrten, aus dem sie Friedrich II. 1239 vertrieben hatte, hiermit etwas zu tun hatten. ${ }^{36}$ Eine Reihe von Dominikanermönchen, die als Inquisitoren fungierten, agierten nachweislich auch als Prediger. ${ }^{37}$ Und zu deren Aufgaben gehörte allem Anschein nach auch die Judenmission.

Bereits 1267 verlieh Karl I. einem Mann namens Manuforte, ,der vom Irrtum des jüdischen Unglaubens zum christlichen Glauben umgekehrt ist und mehr noch in diesem Glauben fest verharrt und sich freilich auch bemüht, andere Juden durch seine Predigt und Ermahnung auf den Weg der Wahrheit zurückzurufen, aus den Einkünften der Färberei der Stadt Trani sechs Unzen Goldes.$^{38}$ Im Jahr 1270 erhob derselbe Manuforte, der einst judeorum Synagoge

35 Solomon Grayzel: Popes, Jews and Inquisition, from „Sicut“ to „Turbato“, in: Aвraham I. Katsh/Leon Nemoy (Eds.): Essays on the Occasion of the seventieth Anniversary of the Dropsie University. Philadelphia 1979, S. 151-188, hier S. 184.

36 Cosimo Damiano Fonseca: Federico II. e gli Ordini Mendicanti, in: Arnold Esch/ Norbert Kamp (Hrsg.): Friedrich II. Tagung des Deutschen Historischen Instituts in Rom im Gedenkjahr 1994. Tübingen 1996, S. 163-181.

37 Acta Capitulorum Provinciae Romanae, ed. Kaeppeli (wie Anm. 24), S. 58: Bartholomeus d'Aquila, Johannes de Sancto Martino (1281) ; S. 90: Guilelmus de Tocco (1288); S. 103: Matheus de Aversa und Angelus de Trano (1291).

38 Giuseppe del Giudice (Ed.): Codice Diplomatico del Regno di Carlo I. e II . d'Angiò. Parte Prima: Carlo I. d'Angiò 1265 a 1285, Vol. 1. Napoli 1863, Nr. 116, S. 314-317: Karolus etc. Noverit Universitas vestra quod nos manuforti de Trano qui a Judayce infidelitatis errore ad fidem christianam conversus nedum in fide ipsa persistit firmiter verum etiam Judeos alios ad viam veritatis predicatione ac exortatione sua revocare conatur sex uncias auri ad generale pondus Regni, in proventibus Tintorie Civitatts Trani presentium tenore concedimus ac etiam assignamus percipiendas ab eodem manuforti de predictis proventibus annis singulis usque ad nostre beneplacitum voluntatis. ... 
Magister gewesen war, dann beim König einen Vorwurf aus dem Repertoire des neuen dominikanischen Antisemitismus, nämlich dass die rabbinische Literatur, vor allem der Talmud, Blasphemien gegen Jesus Christus und die Jungfrau Maria enthielte. Die Justitiare des Reichs erhielten deshalb die Anweisung, auf Veranlassung des Manuforte und mit Rat des Dominikanerpriors und des Franziskanerguardians an den Orten, an die sie von ihnen geführt würden, sorgfältig nachzuforschen, die Bücher zu beschlagnahmen und sie unverzüglich an den Hof zu schicken. ${ }^{39}$

Der Konvertit Manuforte war kein Einzelfall. Doch zeigten wohl nicht alle bekehrten Juden in ihrer neuen Religion einen vergleichbaren Eifer, im Gegenteil. Es ist abermals Manuforte, der dem König im Mai 1270 berichtet, quod multi Iudei ad fidem Christianam conversi fuerunt et deinde ad Iudaismum sunt reversi et latitant in diveris Regni partibus. Diese müssten gezwungen werden, den christlichen Glauben zu bewahren. ${ }^{40}$

Die Verfolgung solcher Juden, die zum Christentum übertraten und später zum Judentum zurückkehrten, war Aufgabe der Inquisition. Galt der relapsus ad iudaismum doch als Apostasie und damit als Häresie. ${ }^{41}$ Doch nicht nur solche relapsi, sondern auch Juden, die niemals konvertiert waren, wurden nun vor das Gericht der Inquisitoren gezogen. Denn bereits im Juni 1270 klagen die Juden Apuliens darüber, dass sie von den Inquisitoren genötigt würden, jene Juden zu denunzieren, die zum christlichen Glauben übergetreten und später zum Judentum zurückgekehrt seien. ${ }^{42}$

Knapp drei Jahre zuvor, am 26. Juli 1267, hatte Papst Clemens IV. die Bulle turbato corde ausgehen lassen. In dieser beauftragte der Papst die Inquisitoren unter Christen und Juden wegen Christen, die zum Judentum übergegangen sind, zu ermitteln, gegen diese wie gegen Häretiker zu verfahren, und auch die Juden, die sie zum Übertritt verleiten mit einer pena debita zu bestrafen. ${ }^{43}$ Zwar ist nicht explizit gesagt, dass es sich bei den genannten Christen, die zum Judentum übergingen, um ehemalige Juden handelte, die zum Christentum übergetreten waren und nun zu ihrer alten Religion zurückkehren wollten. Als Gregor X. die Bulle turbato corde 1274 abermals ausgehen ließ, wurde in diese jedoch ein entsprechender Passus eingefügt, der sich explizit auf jüdische Konvertiten bezog, die des relapsus ad iudaismum beschuldigt wurden. Er blieb Bestandteil aller späteren Neuauflagen der Bulle. ${ }^{44}$ Die späteren Versionen von

39 Del Guidice, Codice Diplomatico (wie Anm. 38). Vol. 3. Napoli 1902, Nr. 122; vgl. Cohen, Friars and the Jews (wie Anm. 4), S. 86.

40 RCA (wie Anm. 21) 4, S. 139.

41 Cohen, Friars and the Jews (wie Anm. 4), S. 48-50; Simonsohn, Apostolic See and the Jews (wie Anm. 9) 7, S. 345-352.

42 RCA (wie Anm. 21) 4, S. 158 f.

43 Simonsohn, Apostolic See and the Jews (wie Anm. 9) 1, Nr. 230.

44 Simonsohn, Apostolic See and the Jews (wie Anm. 9) 1, Nr. 236, 260, 266. 
turbato corde müssen deshalb wohl als Präzisierungen und nicht als Erweiterung der ersten Fassung von 1267 verstanden werden. ${ }^{45}$

In der Bulle turbato corde verbinden sich eine antijüdische Haltung, der ritus der Juden wird als execrabilis bezeichnet, mit dem Bestreben, die Juden kirchlichen Gerichten zu unterstellen. Von allen Versuchen, die Unterstellung der Juden unter kirchliche Gerichte zu begründen, war turbato corde wohl der folgenreichste. Denn die Bulle schuf die rechtliche Grundlage dafür, dass Inquisitoren ihre Kompetenzen tendenziell auf die Juden als Gesamtheit ausdehnen konnten. Voraussetzung war, dass einzelne Juden zum Christentum übergetreten waren und nun im Verdacht standen, zum Judentum zurückgekehrt zu sein. Die Inquisitoren konnten dann auch Juden belangen, die verdächtig waren, ,rückfällige' Konvertiten zu begünstigen, und dies konnte offensichtlich so weit gehen, dass ein jeder Jude mit Zwangsmaßnahmen zu rechnen hatte, der nicht bereit war, verdächtige Konvertiten bei den Inquisitoren anzuzeigen. Denn eben darüber hatten die Juden Apuliens ja bereits 1270 Klage geführt. Bereits vereinzelte Konversionen konnten für die Judengemeinden so zu einer existentiellen Bedrohung werden.

Aus dem Jahr 1281 ist eine Neuauflage der Bulle sicut iudeis überliefert, die offensichtlich Juden aus Sizilien bei Martin IV. erwirkt hatten, ist sie doch nur in Palermo überliefert. Diese weist einen bezeichnenden Zusatz auf, in dem die Befugnisse der Inquisitoren eingeschränkt und Prozesse gegen Juden zumindest teilweise in die Bahnen eines Anklageverfahrens gelenkt werden. Dem Kläger soll zumindest eine Art poena talionis drohen, für den Fall, dass er seine Anschuldigungen nicht beweisen kann. ${ }^{46}$ Außerdem legt sie fest, dass Juden, falls getaufte Juden mit ihnen aliquam familiaritatem hätten, nicht zu irgendeiner Strafe gezwungen werden dürften. ${ }^{47}$ Unmittelbar vor der Sizilischen Vesper wurden die Juden im Reich Karls I. also immer noch von den Inquisitoren belangt, die sie verdächtigten, konvertierte Juden zur Apostasie zu verleiten und für diesen Verdacht reichten offensichtlich bereits soziale Kontakte aus.

Für die Zeit von 1283 bis 1289 fehlen Nachrichten über inquisitorische Aktivität. Die Krise des Königreichs Sizilien infolge der Sizilischen Vesper bedeutete für die Juden des regno also eine Atempause. Ab 1290 jedoch häufen sich die Nachrichten über die Verfolgung der Juden durch die Inquisitoren. Dabei lautet der Vorwurf stets auf Beihilfe zur Apostasie. Vor allem aber stehen die Nachrichten über die Verfolgung und Verurteilung von Juden als fautores

45 Simonsohn, Apostolic See and the Jews (wie Anm. 9) 7, S. 346 mit Anm. 6.

$46 \mathrm{Zu}$ diesem vgl. Winfried Trusen: Von den Anfängen des Inquisitionsprozesses zum Verfahren bei der inquisitio haereticae pravitatis, in: Peter Segl (Hrsg.): Die Anfänge der Inquisition im Mittelalter. (Bayreuther Historische Kolloquien, Bd. 7.) Köln 1993, S. 39-76, hier S. 49.

47 Simonsohn, Apostolic See and the Jews (wie Anm. 9) 1, Nr. 248. 
und receptatores hereticorum nun in unmittelbarer Nachbarschaft zu Zeugnissen über die Konversion von Juden. Die Dynamik der Judenverfolgung, die mit den ersten Übertritten begonnen hatte, erreichte also eine weitere Stufe: Inquisition führte nun zu Massenkonversion.

Anfang 1290 verurteilen die Inquisitoren Jakob de Theate und Bartholomeus d'Aquila einen Juden aus Neapel, namens Ribamelis, ,wegen des Verbrechens der Häresie ... bezüglich des Christen Paulus (!)'- wahrscheinlich ein Konvertit - , der durch jenen Ribamelis und einige andere Juden zum Judentum (zurück)geführt' worden sei, zu einer Buße von 30 Unzen Gold. Von diesen gingen zwei Drittel an die königliche Kammer, ein Drittel an die Inquisitoren. ${ }^{48}$ Dieser Verteilungsschlüssel galt seit Januar $1290 .{ }^{49}$

Doch nicht nur Ribamelis war von den Inquisitoren belangt worden, sondern auch andere Juden aus Neapel, möglicherweise jene, denen vorgeworfen wurde, gemeinsam mit ihm, dem Konvertiten Paulus Beihilfe zum relapsus geleistet zu haben. Auf jeden Fall erhalten wohl Anfang März 1290 die Inquisitoren Andrea de Augusta und Severino de Platia jeder für dieses Jahr 5 Unzen angewiesen de pecunia condenpnacionis Iudeorum Neapolis. ${ }^{50}$ Dieses Geld stammte wahrscheinlich aus dem Verkauf konfiszierten Besitzes. Denn ebenfalls im März 1290 berichten die Inquisitoren Bartholomeus d'Aquila und Iacobus de Theate, dass sie gewisse Häuser und terre laboratorie für den königlichen Fiskus eingezogen und zum Verkauf ausgesetzt haben. ${ }^{51}$

Exakt in die gleiche Zeit wie diese Verfolgung durch die Inquisitoren fällt nun auch eine Reihe von Konversionen von Juden aus Neapel zum Christentum. Denn am 5. und 9. März 1290 ergehen zwei Königsmandate mit fast identischem Wortlaut, in denen 10 namentlich genannte Neofiti aus Neapel, die zuvor zum Christentum übergetreten waren, die Erlaubnis erhalten, eine Synagoge fortan als Oratorium zu nutzen, von der sie versichern, sie habe ihren

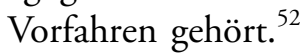

Wie für Neapel 1290, so sind für das apulische Trani 1291 zeitgleich die Verfolgung der dortigen Juden durch die Inquisition und auch zumindest eine

48 RCA (wie Anm. 21) 32, S. 66 f.: ... Cum Ribamelis iudeus de Napoli, servus Camere Regie qui setentialiter estitit condempnatus per religiosos viros fratrem Iacobum de Theate et fratrem Bartholomeum de Aquila, ordinis Predicatorum, generales Inquisitores hereticorum in Regno Sicilie per Sedem Apostolicam constitutos ob crimen heresis, quod per Inquisitores eosdem inventum fuerat contra eum de Paulo Christiano, qui per eundem Ribamelem et quosdam Iudeos alias (!) fuerat ad Iudaysmum reductus, in unciis auri triginta ponderis generalis, solvendis ex ipsis unciis auri viginti Regie Curie et reliquis decem Inquisitoribus supradictis

49 RCA (wie Anm. 21) 32, S. 184.

50 Monti, Da Carlo I a Roberto d'Angio (wie Anm. 23), S. 161, Anm. 11.

51 RCA (wie Anm. 21) 32, S. 68.

52 RCA (wie Anm. 21) 32, S. 62, 195 f. 
Konversion eines Juden zum Christentum belegt. Ende Januar 1291 vermerkt ein Mandat, dass universi iudei Trani durch den Inquisitor Bartholomeus d'Aquila zu einer Strafsumme von 220 Unzen verurteilt worden waren. ${ }^{53} \mathrm{Am}$ 4. Februar 1291 ergeht ein Mandat des Vikars Robert, Graf von Artois, in dem dieser alle ihm Untergebenen anweist, den konvertierten Juden Robert, der in Trani wohnt, gut zu behandeln. ${ }^{54}$

Nicht nur eine unmittelbare zeitliche Nähe, sondern einen fassbaren $\mathrm{Zu}$ sammenhang zwischen der Verfolgung der Juden durch die Inquisitoren und massenhaften Übertritten zum Christentum belegt schließlich ein Mandat des Prinzen Karl Martell an den Strategoten von Salerno und Vikar im dortigen Fürstentum, Petrus de Guinzac. Es datiert auf den 12. April 1292 und fällt damit in jenes Jahr, in dem sich nach allen Indizien der größte Teil der Übertritte der Juden Apuliens und Kampaniens ereignete. In ihm geht es um die Verfolgung der Judengemeinde von Salerno durch den Inquisitor Bartholomeus d'Aquila und den Übertritt fast der gesamten Gemeinde zum Christentum.

Dem Wortlaut des Mandats zufolge hatte der Inquisitor Bartholomeus d'Aquila an den Hof gemeldet, es sei durch glaubwürdige Zeugen bewiesen, dass ,in der großen Synagoge der Juden von Salerno mit Wissen und Mitwissen der Juden der Judayca von Salerno, denen die Synagoge gehörte, viele Häretiker und Abtrünnige vom Glauben Christi Aufnahme fanden, dort ein gewisser Christ namens Moyses beschnitten wurde, gewisse andere der Juden sich zur Häresie bekannten und im Becken der Synagoge ein gewisser Apostat vom Glauben Christi, Azarias, durch die Juden der Judayca in Verletzung der Taufe abgewaschen wurde.' Er habe deshalb ,aufgrund der ihm übertragenen Machtbefugnis angeordnet, ,dass die Synagoge den kanonischen Strafen gemäß bis auf die Grundmauern eingerissen' werden sollte, wobei er sich bezüglich der Synagoge und ihres Besitzes vorbehielt, ,über sie auch anderweitig zu verfügen, wenn es der Verbreitung des Glauben förderlich sein werde'.

Da am folgenden Tag tatsächlich ,das Licht des katholischen Glaubens die Juden der genannten Judayca fast alle erleuchtete, unter denen der Großteil zum ersten Mal schlimme Armut litt änderte er den Spruch, dass die genannte Synagoge zerstört werden solle und ordnete bezüglich jener Synagoge an, dass sie zu Geld gemacht werden solle, aus dem für die genannten, in der heiligen Taufe Armen vorgesorgt werden solle. Er befahl, die Synagoge durch zwei seit jeher christliche und getreue Prokuratoren zu verkaufen, und den daraus erhaltenen Preis unter den genannten Armen zu teilen und verteilen, so wie es durch seinen schriftlich festgehaltenen Urteilsspruch feststünde'.

Dem allerdings hatte sich der Strategot Guinzac entgegengestellt und von den Prokuratoren des Inquisitors zwei Drittel des erzielten Preises für den Hof

53 RCA (wie Anm. 21) 35, S. 211.

54 RCA (wie Anm. 21) 35, S. 214. 
verlangt. Aus diesem Grund hatte Bartholomeus d'Aquila beim Hof darum gebeten, die Krone möge zugunsten der nunmehr verarmten ehemaligen Juden auf die ,zwei Teile des Kaufpreises für die genannte Synagoge, die dem Hof zustehen', verzichten. Und die Gewährung dieser Bitte bildete den Rechtsinhalt des Mandats an den Strategoten. ${ }^{55}$

Der Inquisitor Bartholomeus d'Aquila behauptete also, in der Hauptsynagoge von Salerno würden konvertierte Juden rituell wieder zum Judentum zurückgeführt und hatte deshalb praktisch die gesamte Judengemeinde der Stadt nicht nur beschuldigt, Beihilfe zur Apostasie zu leisten, sondern diesen Vorwurf offensichtlich auch zum Anlass für einen regelrechten Inquisitionsprozess gegen die Judengemeinde von Salerno genommen, an dessen Ende ein Schuldspruch stand. Der Inquisitor betont, dass, rechtmäßige Zeugen' die Quelle seines

55 RCA (wie Anm. 21) 40, S. 72 f.: Pro fratre Bartholomeo de Aquila. Karolus primogenitus illustris Ierusalem et Sicilie regis, princeps Salernitanus et honoris Montis S. Angeli dominus ac eius in regno Sicilie vicarius, nobili viro domino Petro de Guinsac, militi vicario in Principatu et stratigoto Salerni devoto suo, salutem et dilectionem sinceram. Exposuit excellentie nostre religiosus vir frater Bartholomeus de Aquila ordinis Fratrum Predicatorum inquisitor heretice pravitatis in regno Sicilie per sedem apostolicam constitutus, quod, dum pridem per legitimos testes, sibi plene conscientie quod in sinagoga maiori Iudeorum de Salerno, scientibus et conscientibus Iudeis Iudayce Salernitane ad quos predicta sinacoga spectabat, plures heretici apostate a fide Christi receptati fuerant in ea et quidem Christianus nomine Moyses fuerat circoncisus ibidem et quidam alii Iudeorum heresim profexi et in puteo vel fonte ipsius Sinagoge quidam nomine Azarias a fide Christi apostate in inuriam baptismatis per Iudeos Iudaice predicte fuerat ablutus. Ideo Sinagogam eandem iuxta canonicas sanctiones auctoritate sibi commissa mandaverit funditus dirui, reservata tamen in potestate ipsius super predicta Sinagoga et bonis eiusdem, ut possit alter de ipsis disponere si promotione fidei foret expediens. Sed, quia sequenti die divina gratia Iudeos Iudayce predicte universaliter fere illuminavit lumen catholice fidei, inter quos maior pars male primitus paupertatis, sententiam de predicta Sinagoga diruenda commutans et disponens de ipsa Sinagoga ut in pecunia convertatur, de qua in sacro baptismate provideatur pauperibus supradictis, Sinagogam eandem vendi mandavit per duos procuratores christianos antiquos et fideles, et pretium acceptatum de ipsa dividendum et dispensandum per pauperes supradictos, prout per sententiam ipsius latam in scriptis asserit plene constare, vos predictos procuratores christianos, contra predictam sententiam fratris Bartholomei in venditione dicte Sinagoge, petentes ab ipsis pro parte Curie nostre duas partes pretii Sinagoge ipsius molestatis et multipliciter perturbatis; propter quod nobis humiliter supplicavit ut providere super hoc misericorditer dignaremur. Nos igitur, volentes cum eisdem pauperibus misericorditer agere ne paupertate oppressi et noviter ipsi conversi ad fidem nondum renati sacro baptismate scandalum patiantur, predictas duas partes pretii dicte Sinagoge contigentes Curiam nostram divine pietatis intuytu pro eorum vestibus et elemosina pauperibus ipsis de speciali gratia relaxamus, volentes et devotioni vestre districte mandantes quatenus predictos procuratores christianos in venditione dicte Sinagoge et receptione pecunie pro ipsius pretio de cetero nullatenus molestetis, nec impendimentum aliquod propterea prestetis eisdem, immo favorem et auxilium impendatis in venditione Sinagoge predicte, ita quod ad nostram propterea recurrere Curiam non cogantur. Datum Neapoli, anno domini MCCXCII die XII mensis aprilis $V$ indictionis. 
Wissens seien, seine Anordnungen trifft er ,aufgrund der ihm übertragenen Machtbefugnis' bzw. ,den kanonischen Strafen gemäßs.

Folge einer Verurteilung als Häretiker war in der Regel die Konfiskation des Vermögens. Beihilfe zur Häresie wurde regelmäßig mit Geldbußen geahndet. Dies galt in besonderem Maße für jüdische fautores, denn diese konnten die Inquisitoren ja nicht zum Tragen von Kreuzen, Wallfahrten oder anderen Bußen verurteilen. ${ }^{56}$

Dass der Inquisitor das Gemeindevermögen der Juden infolge seines Schuldspruchs konfiszieren ließ, liegt klar zutage. Forderte der königliche Amtsträger vor Ort doch zwei Drittel des Preises, den die Prokuratoren des Inquisitors beim Verkauf der Synagoge erzielt hatten, für die Krone und damit jenen Anteil, der der königlichem Kammer vom Vermögen eines verurteilten Häretikers zustand.

Doch die Juden von Salerno gingen nicht nur ihres Gemeindevermögens, sondern offensichtlich auch beträchtlicher Teile ihres Privatvermögens verlustig. Der Großteil von ihnen litte, zum ersten Mal üble Armut' bzw. sie seien, in der heiligen Taufe Arme', betonte der Inquisitor und begründet hiermit seine Bitte, die Krone möge zugunsten der nunmehr verarmten Konvertiten auf die zwei Drittel des Gemeindevermögens verzichten, die ihr zustehen. Die hier gleichsam chiffrierte Ursache für die plötzliche Armut des Großteils der Salernitaner Juden kann aus der Logik der Vorgänge nur gewesen sein, dass der Inquisitor auch ihr Vermögen hatte konfiszieren lassen bzw. ihnen hohe Geldbußen auferlegt hatte, waren sie doch als Apostaten bzw. fautores et receptatores hereticorum verurteilt worden. Dass der Hof zustimmte, auf seinen Anteil am Verkaufspreis der Synagoge zu verzichten, wird ihm in Anbetracht der Tatsache, dass ja zwei Drittel dieses konfiszierten Vermögens und der Geldbußen an die königliche Kammer fielen, nicht allzu schwer gefallen sein.

Die Vorgänge in Salerno vermitteln einen Eindruck davon, wie die Inquisitoren im Königreich Neapel in den 90er Jahren des 13. Jahrhunderts die Möglichkeiten nutzen, Juden zu verfolgen, die ihnen die Bulle turbato corde eröffnet hatte, und wie sie auf diese Weise den massenhaften Übertritt von Juden zum Christentum herbeiführen. Dass Juden einzelne Konvertiten angeblich oder tatsächlich zum relapsus verleiten und dass dies in der Synagoge geschieht, bietet den Anlass dafür, eine ganze Judengemeinde als fautores et recepatores anzuklagen und zu verurteilen. Und die finanzielle Bedrängnis, in die er die Juden durch die Konfiskationen bzw. Geldbußen gebracht hat, die aus seinem Schuldspruch resultierten, benutzt der Inquisitor Bartholomeus d'Aquila

56 Yosef Hayim Yerushalmi: The Inquisition and the Jews of France in the Time of Bernard Gui, in: Harvard Theological Review 63, 1970, S. 317-376, hier S. 349; vgl. auch den Fall des 1290 in Neapel wegen Beihilfe zum relapsus verurteilten Juden Ribamelis o. bei Anm. 48. 
dann als Druckmittel, um diese zum Übertritt zu bewegen. Denn es ist auffällig, dass der Inquisitor zwar anordnet, ,dass die Synagoge den kanonischen Strafen gemäß bis auf die Grundmauern eingerissen werden sollte', sich gleichzeitig aber vorbehält, ,über sie auch anderweitig zu verfügen, wenn es der Verbreitung des Glauben förderlich sein werde'. Man tut dem Zeugnis wohl keine Gewalt an, wenn man hierin ein Angebot erkennt, das der Inquisitor den verarmten Salernitaner Juden machte, und das diese offensichtlich nicht ablehnen konnten. Denn tags darauf erleuchtete ja ,das Licht des katholischen Glaubens fast alle Juden der genannten Judayca'.

Dass die Inquisitoren nicht nur die Juden von Salerno in finanzielle Bedrängnis gebracht und daraus ein wichtiges Druckmittel gewonnen hatten, um sie zum Übertritt zu bewegen, dafür sprechen auch die Privilegien, mit denen Karl II. 1294 die konvertierten Juden auf Lebzeiten von allen Abgaben und Steuern befreite. ${ }^{57}$ Solche Steuerbefreiungen gewährte die Krone in der Regel, wenn die wirtschaftliche Leistungskraft der Betroffenen, etwa einer Gemeinde oder Region, stark geschwächt war, aus welchen Gründen auch immer. Offensichtlich hatten die konvertierten Juden also auch andernorts erheblichen finanziellen Schaden erlitten. Allerdings sind für die Folgezeit auch Neofiti belegt, die über erhebliches Vermögen verfügten. ${ }^{58}$ Die konvertierten Juden waren also nicht alle in gleichem Maße finanziell geschädigt worden. Vielleicht hatten einzelne Juden auch versucht, einer Verurteilung als fautores et receptatores durch Konversion zuvorzukommen.

Wer einmal von den Inquisitoren verurteilt worden war, schwebte zudem ständig in der Gefahr weiterer Verfolgung. Die Inquisitoren konnten die Höhe der Geldbuße auch im Nachhinein noch erhöhen, oder sogar die Inhaftierung anordnen, ohne dass neue Anschuldigungen erhoben worden wären. Letzteres drohte vor allem denjenigen, die auch nach einer Verurteilung durch den Inquisitor noch Kontakt zu konvertierten Juden pflegten, die zum Judentum zurückgekehrt waren. Diese und andere Gefahren, wie die Verurteilung zu Exil oder indirekter Exkommunikation, also Boykott durch die Christen, wird wahrscheinlich ebenfalls manch einen Juden im Königreich Neapel zur Flucht in den Übertritt veranlasst haben. ${ }^{59}$

Die Logik, der die Verfolgung der Juden des regno durch die Inquisitoren folgte, war so einfach wie folgenreich. Sie bestand in der Anwendung des

57 S.o. bei Anm. 27.

58 CDB (wie Anm. 31) 13, Nr. 103; 116; 124, 127, 128.

$59 \mathrm{Zu}$ den Strafen für fautores und receptatores von relapsi vgl. VitTore Colorini: Ebrei in Ferrara nei secoli XIII e XIV, in: Ders.: Judaica Minora. Saggi sulla Storia dell'Ebraismo Italiano dall'Antichità all'Età Moderna. Milano 1983, S. 147-188, hier S. 161, 184 f.; vgl. auch Yerushalmi, The Inquisition and the Jews of France (wie Anm. 56), S. $348-$ 350 . 
Ketzerrechts nicht nur auf jüdische Konvertiten, die der Apostasie, sondern auch auf Juden, die der Beihilfe dazu verdächtigt wurden.

Dieser Logik setzte die Monarchie nur zu Beginn noch einen gewissen Widerstand entgegen. Denn 1270 hatte Karl I. der Bitte der apulischen Juden noch entsprochen, den Inquisitoren zu untersagen, sie zu zwingen, dass sie rückfällige Konvertiten denunzierten. ${ }^{60}$ Als sizilianische Juden elf Jahre später versuchten, Schutz vor den Inquisitoren zu erhalten, wandten sie sich jedoch bezeichnenderweise nicht an ihren König, sondern an den Papst. ${ }^{61}$ Offensichtlich erwarteten sie vom Königshof keinen wirksamen Schutz.

Für Karls I. gleichnamigen Nachfolger ist dann eindeutig belegt, dass die Monarchie die Inquisitoren bei der Verfolgung der Juden unterstützte. Davon zeugen etwa die Vorgänge von Salerno im Jahre 1292. Denn hier wird der königliche Amtsträger vor Ort explizit angewiesen, die Prokuratoren des Inquisitors beim Verkauf der Synagoge in keiner Weise zu behindern, sondern zu unterstützen. ${ }^{62} \mathrm{Im}$ Dezember des gleichen Jahres weist sein Sohn Karl von Ungarn den Kapitan von Lucera an, gewisse Juden, hereticorum receptatores, fauctores et defensores, die vor den Inquisitoren nach Lucera geflohen seien und dort sich aufhielten, festzunehmen und an die Inquistoren Guilelmus de Tocco und Johannes de Sancto Martino auszuliefern. ${ }^{63}$ Ebenfalls als Begünstigung der inquisitorischen Judenverfolgung wird man es werten müssen, dass Karl II. den Inquisitoren Anfang 1290 für die Ausübung ihres officiums ein Drittel der Summen überließ, die sie durch Konfiskationen und Geldbußen einnahmen. Erging dieses Privileg doch an jene Inquisitoren, die unmittelbar danach gegen die Juden von Neapel vorgingen. Dass die Inquisitoren nun nicht mehr, wie zur Zeit Karls I. feste jährliche Gagen erhielten, sondern die Höhe ihrer Einkünfte mit der Anzahl ihrer Verurteilungen und den aus diesen resultierenden Geldbußen und Konfiskationen korrespondierte, wird die Dynamik der inquisitorischen Judenverfolgung wohl eher befördert als gebremst haben.

Doch nicht nur die Judenverfolgung durch die Inquisition, sondern auch die Bekehrung von Juden wurde von der Monarchie in der Zeit Karls II. aktiv unterstützt. Einige in diesem Zusammenhang bisher übersehene bzw. unbekannte unmittelbar zeitgenössische Mandate, die in den Registern der königlichen Kanzlei überliefert wurden, belegen, dass Mitglieder des Königshauses sich aktiv an der Bekehrung von Juden beteiligten, indem sie Taufpatenschaften übernahmen. Schon im Jahr 1291 ist es der Vikar Robert von Artois, der einen Juden aus der Taufe hebt und ihm seinen Namen gibt. ${ }^{64}$ Wohl im September

60 RCA (wie Anm. 21) 4, S. 158 f.

61 Simonsohn, Apostolic See and the Jews (wie Anm. 9) 1, Nr. 248.

62 RCA (wie Anm. 21) 40, S. 73.

63 CDSL (wie Anm. 23), Nr. 85.

64 RCA (wie Anm. 21) 35, S. 214. 
1295 wendet sich ein clericus neofitus aus Neapel namens Philippus dictus de Principe, quem Philippus filius noster Princeps Tarentinus de sacro fonte suscepit, an den Hof Karls II., der vom König eine Pfründe versprochen bekommen hatte. ${ }^{65}$ Und im März 1296 erhält der Strategot von Salerno die Anweisung, jährlich aus den Einnahmen der Steuerverpachtung eine Unze an den Vormund eines Teobalducio ... neofito zu zahlen, den die Schwiegertochter Karls II., Clementia von Habsburg aus der Taufe gehoben hatte. ${ }^{66}$ Dabei war die Gattin des Thronfolgers Karl Martell am Taufbecken vielleicht sogar mit dem Inquisitor Bartholomeus d'Aquila zusammengetroffen. Denn von den namentlich belegten 150 männlichen Juden, die infolge der Judenverfolgung 1292 in Salerno die Taufe nahmen, heißen nicht weniger als 5 Bartholomeus, davon zwei sogar genau wie der Inquisitor Bartholomeus d'Aquila. ${ }^{67}$

Mit ihrer Unterstützung der inquisitorischen Judenverfolgung beschritt die Monarchie der süditalienischen Anjou in ihrer Zeit einen Sonderweg. Zwar versuchten Inquistoren am Ende des 13. und zu Beginn des 14. Jahrhunderts auch in anderen Regionen Südeuropas, Juden zu verfolgen, die sie beschuldigten, fautores et receptatores von Konvertiten zu sein, die zum Judentum zurückgekehrt waren. ${ }^{68}$ Die weltlichen Gewalten unterstützen sie dabei in der Regel jedoch nicht vorbehaltlos, im Gegenteil. Es ist vielfach belegt, dass Inquisitoren auf harten Widerstand der weltlichen Autoritäten trafen, wenn sie versuchten, Juden vor ihre Tribunale zu zitieren.

Im Königreich Aragon verfolgte das Königtum dabei um 1300 eine sehr konsequente Linie. ${ }^{69}$ Bereits Peter III. wies 1284 seine officiales explizit an, den Inquistoren zu verbieten, gegen Juden vorzugehen, die als receptatores apostasieverdächtiger Konvertiten verdächtigt wurden, und behielt sich eine etwaige Bestrafung der Juden für sich selbst vor. ${ }^{70}$ Und sein Nachfolger Jaume II. wiederum beschied 1292 den Inquisitoren, dass es seine Angelegenheit sei, die Juden gegebenenfalls zu strafen, und nicht die der Inquisitoren, da die Juden

65 Archivio di Stato di Napoli, Ricostruzione Angioina VII/3, f. 112, nach RA 1295 B, fol 13. t.

66 Codice Diplomatico Salernitano del Secolo XIII. (CDS) Vol. 3 - Salerno dal 1282 al 1300, ed. Carlo Carucci. Subiaco 1946, Nr. 257.

67 RCA (wie Anm. 21) 35, S. 214.

68 Simonsohn: Apostolic See and the Jews (wie Anm. 9) 7, S. $347 \mathrm{f}$.

69 Yom Tov Assis: The Papal Inquisition and Aragones Jewry in the fourteenth century, in: Mediaeval Studies 49, 1987, S. 391-440, 400-402; Ders.: The golden Age of the Aragonese Jewry. Community and Society in the Crown of Aragon, 1213-1327. London/Portland Or. 1997, S. 59-62; Fritz Baer: Studien zur Geschichte der Juden im Königreich Aragonien während des 13. und 14. Jahrhunderts. (Historische Studien, H. 106.) Berlin 1913 (Ndr. Vaduz 1965), S. 63; Grayzel, Popes, Jews, and Inquisition (wie Anm. 35), S. $181 \mathrm{f}$.

70 Jean Regné: History of the Jews in Aragon. Regesta and Documents 1213-1327, ed. Yom Tov Assis. Jerusalem 1978, Nr. 1101, 1206. 
nicht dem katholischen Glauben angehörten, noch den Gesetzen der Kirche unterstünden. ${ }^{71}$ Noch 1323 lud er den Inquisitor Bernardus de Podio vor, weil dieser ohne den König zuvor informiert zu haben, gegen die Juden von Tarragona vorging. ${ }^{72}$

In Frankreich unterstützte das Königtum die Inquisitoren am Ende des 13. Jahrhunderts phasenweise. Allerdings wies Philipp IV. wiederholt Ansprüche der Inquisitoren zurück, Jurisdiktion über Juden auszuüben und bremste so die inquisitorische Judenverfolgung. ${ }^{73}$ So ergeht 1293 die Anweisungen an königliche Amtsträger, darauf zu achten, dass die Juden nicht ohne die Zustimmung der weltlichen Autorität belangt werden dürfen. ${ }^{74}$ Im Jahr 1299 ermächtigt König Philipp die Inquisitoren zwar vorübergehend, Juden zu verfolgen, die Christen ,zur häretischen Vederbtheit verlocken' ${ }^{75}$ Drei Jahre später jedoch verbot er den Inquisitoren wieder kategorisch, gegen Juden vorzugehen. ${ }^{76}$

Eine ähnliche Haltung gegenüber den Inquisitoren nahmen auch Karl I. und Karl II. von Anjou ein: als Grafen der Provence. ${ }^{77}$ Auch in der Provence wechselten sich Phasen, in denen die weltliche Autorität die Inquisitoren unterstützte, ab mit Phasen des Widerstands gegen die Inquisitoren, so dass auch hier die inquisitorische Judenverfolgung immer wieder durch die weltliche Autorität gebremst wurde.

Am 25. März 1276 untersagte Karl I. Anjou auf Bitten einer Delegation provençalischer Juden den Inquisitoren, die Juden der Grafschaft Provence zu verfolgen, denen sie viele unangebrachte und unrechtmäßige gravamina zugefügt hätten, außer in den drei Fällen, die die Bulle turbato corde vorsehe. Wollten sie den Juden Geldbußen auferlegen, so müssten sie zuvor den gräfli-

71 Fritz Baer (Hrsg.): Die Juden im christlichen Spanien. Erster Teil: Urkunden und Regesten. I. Aragonien und Navarra. (Veröffentlichungen der Akademie für die Wissenschaft des Judentums, Historische Sektion, Bd. 4.) Berlin 1929, Nr. 133.

72 Heinrich Finke: Acta Aragonensia. Quellen zur deutschen, italienischen, französischen, spanischen, zur Kirchen- und Kulturgeschichte aus der diplomatischen Korrespondenz Jaymes II. (1291-1327). Bd. 2. Berlin/Leipzig 1908, Nr. 540.

73 William Chester Jordan: The French Monarchy and the Jews. From Philip Augustus to the last Capetians. Philadelphia 1989, S. 187 f.; Grayzel, Popes, Jews, and Inquisition (wie Anm. 35), S. $182 \mathrm{f}$.

74 Gustave Saige: Les Juifs du Languedoc antérierement au XIVe Siècle. Paris 1881 (Ndr. 1971), Nr. 43/18.

75 SAIGE, Les Juifs du Languedoc (wie Anm. 74), Nr. 20.

76 Siméon Luce (Ed.): Catalogue des Documents du Trésor des Chartes relatifs aux Juifs sous le Règne de Philippe le Bel, in : REJ 2, 1881, Nr. 15.

77 Kiesewetter, Anfänge der Regierung Karls II. (wie Anm. 7), S. 518-521; Grayzel, Popes, Jews, and Inquisition (wie Anm. 35), S. 183; vgl. auch Josef Shatzmiller: L'inquisition et les juifs de Provence au XIII ${ }^{\mathrm{e}}$ s., in: Provence Historique 23, 1973, S. 327-338; Maurice Kriegel: Prémarranisme et inquisition dans la Provence des $\mathrm{XIII}^{\mathrm{e}}$ et XIV ${ }^{\mathrm{e}}$ siècles, in: Provence Historique 24, 1974, S. 313-323. 
chen Hof konsultieren. ${ }^{78}$ Auch Karl II. zeigt sich widerholt bestrebt, die inquisitorische Judenverfolgung durch gräfliche Beamte zu kontrollieren und widersteht dabei auch päpstlichen Druck. Denn Papst Nikolaus IV. hatte den Inquisitoren der Provence 1288 befohlen, die Juden zu verfolgen, die konvertierten Juden Beihilfe zum relapsus leisten und 1290 die örtlichen Prälaten angewiesen, die Inquisitoren dabei zu unterstützen. ${ }^{79}$

Am 7. Oktober 1291 befahl Karl II. den Seneschallen der Provence jedoch, darauf zu achten, dass sie die Juden nicht festnehmen oder festzunehmen befehlen, außer in den Fällen, die in den päpstlichen Schriftstücken genannt sind, mit den sich Inquisitoren autorisieren. Sollte es diesbezüglich irgendwelche Zweifel geben, sollten sie die Juden keinesfalls festnehmen, ohne vorher den Hof informiert zu haben. ${ }^{80}$ Und am 27. Juni 1292 und noch einmal am 13. Juli 1293 erteilt Karl II. den gräflichen Amtsträgern in der Provence abermals die Anweisung, Inquisitoren, die ihre Befugnisse überschritten, nicht mehr zu unterstützen, sondern diese daran zu hindern. ${ }^{81} \mathrm{Im}$ darauffolgenden Jahr bestätigt der Graf den provençalischen Juden dann sämtliche Privilegien Karls I. und untersagt ausdrücklich, ihnen irgendwelche Belästigungen und Unrecht zuzufügen. ${ }^{82}$

Die Könige von Aragon und Frankreich und auch der Graf der Provence traten den Inquisitoren wiederholt entgegen, wenn diese Juden auf der Basis des Beihilfe-Vorwurfs verfolgen wollten, weil sie hierin eine Beeinträchtigung ihrer Rechte sahen. ${ }^{83}$ Beanspruchten sie die Juden doch als ,ihre' Juden. Diese direkte Unterstellung der Juden unter den König bzw. den Grafen hieß vor allem, dass dieser die Jurisdiktion über die Juden und die Einkünfte aus den Judensteuern ausschließlich sich selbst vorbehielt. Der fuero, also das Stadtrecht der aragonesichen Stadt Teruel von 1176 ist bekanntlich der älteste Beleg dafür, dass Juden in Europa als servi regis, die ,allzeit dem königlichen Fiskus zugehörig' seien (semper fisco regio deputati). ${ }^{84}$ Auch die franzöische Monarchie pochte auf

78 Alain de Bouard (Ed.): Actes et Lettres de Charles Ier Roi de Sicile concernant la France (1257-1284). Paris 1926, Nr. 946.

79 Les Registres de Nicolas IV. (1288-1292). Recueil des bulles de ce pape publiés ou analysées d'après le manuscrit original des Archives du Vatican, ed. ERnEST Langlois. 2 Bde. Paris 1886/93, Nr. 320, 321; Simonsohn, Apostolic See and the Jews (wie Anm. 9) $1, \mathrm{Nr} .263 \mathrm{f}$.

80 RCA (wie Anm. 21) 40, S. 90 f.; Das Mandat ist teilweise wörtlich identisch mit dem König Philipps IV. Von Frankreich von 1293 (s. o. Anm. 74).

81 Giobbe Ruocco: Regesto Anioino-Francescano del regno di Napoli, in: Miscellanea Francescana 38, 1938, Nr. 60, 64.

82 Kiesewetter, Anfänge der Regierung Karls II. (wie Anm. 7), S. 520.

83 Yerushalmi, The Inquisition and the Jews of France (wie Anm. 56), S. 320 f.; GrayZel, Popes, Jews, and Inquisition (wie Anm. 35), S. 172, 180-183.

84 Alexander Patschovsky: Das Rechtsverhältnis der Juden zum deutschen König (9.-14. Jahrhundert, in: ZRG GA 110, 1993, S. 331-371, hier S. 353; David Abu- 
eine direkte unmittelbare Unterordnung der Juden unter die Königsherrschaft, auch wenn dies bis zum Beginn des 13. Jahrhunderts nur die Juden der Krondomäne betraf. ${ }^{85}$ Und als Graf der Provence hatte Karl I. von Anjou 1270 dort selbst die gräfliche tallia judeorum eingeführt. ${ }^{86} \mathrm{Als}$ er den Inquisitoren 1276 untersagte, den provençalischen Juden Geldbußen aufzuerlegen, begründete er dies folgerichtig damit, dass dieses Geld ihm und seiner curia gehöre. ${ }^{87}$ Die Versuche Karls II. aus den frühen neunziger Jahren des 13. Jahrhunderts, die Juden der Provence vor übermäßiger Verfolgung durch die Inquisitoren zu schützen, gehen Hand in Hand mit einer Erhöhung der gräflichen Judensteuer von 600 auf 1600 Unzen jährlich. ${ }^{88}$

\section{Zwischen Königtum und Kirchen: Die politische Stellung der Juden im mittelalterlichen Süditalien}

Auch als Könige von Sizilien bzw. Neapel beanspruchten Karl I. und Karl II. eine direkte unmittelbare Unterordnung der Juden unter die königliche Kammer. Allerdings konkurrierten sie dabei vielerorts mit anderen, lokalen Gewalten. Denn Jurisdiktion über die Juden und Einkünfte aus den Judensteuern wurden in Süditalien am Ende des 13. Jahrhunderts in fast allen Orten mit bedeutenden jüdischen Gemeinden ganz oder teilweise von lokalen kirchlicher Gewalten beansprucht, vor allem von Bischofskirchen, aber auch von einigen bedeutenden Abteien. Umstritten waren vor allem die indirekten Steuern aus dem Färbereigewerbe, das die Juden vielerorts als ursprünglich königliches Monopol ausübten und das im mittelalterlichen Süditalien dermaßen charakteristisch für die Juden war, dass iudecca und tintoria vielfach als Synonyme gebraucht wurden.

Die Kirchen konnten sich vielfach, nicht immer, auf königliche Privilegien berufen, mit denen sie die Gerichtsbarkeit über die Judengemeinden und die Einkünfte aus den direkten und indirekten Judensteuern übertragen bekommen

LAFIA: The Servitude of Jews and Muslims in the Medieval Mediterranean: Origins ad Diffusions, in: Mélanges de l'École Française de Rome 112, 2000, S. 687-714, hier S. $689 \mathrm{f}$.

85 Jordan, The French Monarchy and the Jews (wie Anm. 73), S. 3-23; Gavin I. Langmuir: "Judei Nostri“ and the Beginning of Capetian Legislation, zuletzt in: Ders.: Toward a Definition of Antisemitism. Berkeley/Los Angeles/Oxford 1990, S. 137-166; Ders.: „Tamquam Servi“: The Change in Jewish Status in French Law about 1200, zuletzt in: Ebd., S. 167-194.

86 Hierzu zuletzt Joseph Shatzmiller: Encore la Tallia Judeorum, in: Gabrielle SedRajna (Ed.): Rashi. 1040-1990. Hommage à Ephraim E. Urbach. Paris 1993, S. 589-597.

87 S. o. Anm. 78.

88 Kiesewetter, Anfänge der Regierung Karls II. (wie Anm. 7), S. 492 f. 
hatten. Diese datierten teilweise bis in die Zeit vor der Errichtung der normannischen Einheitsmonarchie zurück. ${ }^{89}$ Viele Privilegien, auf die sich die Herrschaft der Kirchen über die Juden am Ende des 13. Jahrhunderts stützte, stammten jedoch aus der Krisenphase des Königtums, die mit dem Dynastiewechsel von den Hauteville zu den Staufern am Übergang vom 12. zum 13. Jahrhundert verbunden war. $^{90}$

Die politische Situation der Juden in Süditalien bis zum Ende des 13. Jahrhunderts sollte dann maßgeblich davon bestimmt werden, dass die Monarchie seit der Rückkehr Friedrichs II. in das Königreich Sizilien 1220 versuchte, die Judensteuern wieder stärker an die königliche Kammer fließen zu lassen. Denn hierdurch entstand ein Konflikt zwischen Monarchie und Kirchen um die Judengemeinden, der sich auch nach dem Dynastiewechsel von den Staufern zu den Anjou fortsetzte und ohne den sich der Erfolg der inquisitorischen Judenverfolgung nicht erklären lässt.

Folgenreich war vor allem, dass Friedrich II. im Rahmen seiner Wirtschaftsreformen, der sogenannte nova statuta, zu Beginn der 30er Jahre des 13. Jahrhunderts auch die Färbereien neu organisieren ließ, um so die Steuern, die auf gefärbten Stoffen lagen, wieder für die königliche Kammer einzuziehen. ${ }^{91}$ Sämtliche Färbereien von Prälaten, Grafen und Baronen, die das königliche Färbereimonopol unterliefen, wurden geschlossen, und an allen Orten die Färberei wieder in königliche Verwaltung genommen, die von eigens dazu

89 Raffael Strauss: Die Juden im Königreich Sizilien unter Normannen und Staufern. (Heidelberger Abhandlungen zur mittleren und neueren Geschichte, H. 30.) Heidelberg 1910 (Ndr. Nendeln 1977), S. 19 f.; Hubert Houben: Gli ebrei nell'Italia meridionale tra la metà dell'XI e l'inizio del XIII secolo, in: Fonseca/Luzzati/Tamani/ColafemMINA (Eds.): L'Ebraismo dell'Italia Meridionale Peninsulare, S. 47-63, hier S. 60-62; Ders.: Möglichkeiten und Grenzen religiöser Toleranz im normannisch-staufischen Königreich Sizilien, in: DA 50, 1994, S. 159-198, hier S. 171.

90 Tancredi et Wilhelmi III. Regum Diplomata, ed. Herbert Zielinski. (Codex Diplomaticus Regni Siciliae. Series Prima: Diplomata Regum et Principum e Gente Normannorum, T. 5.) Köln/Wien 1982, Nr. 18, 33; Constantiae Imperatricis Diplomata, ed. Theo Kölzer. (MGH Diplomata Regum et Imperatorum Germaniae, T. XI, Pars III) Hannover 1990, Nr. 59, 60, Dep. 36, 57; Friderici II. Diplomata inde ab Anno MCXCVIII. Usque ad Annum MCCXII, ed. Walter Koch. (MGH Diplomata Regum et Imperatorum Germaniae, T. XIV, Pars I) Hannover 2002, Nr. 70.

$91 \mathrm{Zu}$ den Wirtschaftsreformen Friedrichs II. und ihren Folgen vgl. Erich Maschke: Die Wirtschaftspolitik Kaiser Friedrichs II im Königreich Sizilien, zuletzt in: Gunther G. Wolf (Hrsg.): Stupor Mundi. Zur Geschichte Friedrichs II. von Hohenstaufen. (Wege der Forschung, Bd. 101.) 2. neubearb. Aufl. Darmstadt 1982, S. 349-394; NorberT Kамг: Vom Kämmerer zum Sekreten. Wirtschaftsreformen und Finanzverwaltung im staufischen Königreich Sizilien, in: Josef Fleckenstein (Hrsg.): Probleme um Friedrich II. (Vorträge und Forschungen, Bd. 16.) Sigmaringen 1974, S. 43-92, v. a. S. 56-58; William A. Percy: The Indirect Taxes of the medieval Kingdom of Sicily, in: Italian Quarterly 85, 1981, S. 73-85. 
eingesetzten jüdischen magistri ausgeübt wurde. ${ }^{92}$ Dort, wo Bischöfe und Äbte bis dato aufgrund königlicher Privilegien die Färberei besessen hatten, wurde diese nun durch Fixsummen abgelöst, die dem Durchschnittswert der Steuereinnahmen der letzen Jahre entsprachen. ${ }^{93}$ „Die Gewinne der Zukunft wollte der Staat nicht mit der Kirche teilen". ${ }^{94}$

Die Reaktionen der betroffenen Kirchen hierauf fielen unterschiedlich aus. In Tarent etwa hatte der dortige Erzbischof offensichtlich nichts gegen diese Neuregelung einzuwenden und begnügte sich mit den zehn Unzen, die die Vorsteher der Färberei jährlich an ihn abführen mußten. Allerdings hatte die Reorganisation des Färbereimonopols in Tarent auch nicht zu wesentlich höheren Einnahmen geführt. Den Zeugenaussagen einer Enquète über die Rechte des Bistums an den königlichen Einkünften aus dem Jahr 1247 zufolge betrugen sie in jenen Jahren zwischen 10 und 12 Unzen. ${ }^{95}$ Es flossen also weiterhin zwischen 83 und 100 Prozent der Einkünfte aus der Färberei an den Bischof.

Allerdings waren die Kirchen nicht überall bereit, sich auf diesen Handel einzulassen, wie der Konflikt Friedrichs II. mit den Mönchen von Montecassino zeigt. Dem Bericht Richards von San Germano zufolge hatten im September 1231 zunächst der Erzbischof von Reggio di Calabria den zwei Juden, die im Auftrag des Kaisers die iudeca von San Germano in Empfang nehmen sollten, verboten, sie zu beschlagnahmen, ,und ihnen befohlen, dass sie sie in Frieden im Besitz des Klosters Monte Cassino lassen sollten' ${ }^{96}$ Die königlichen officiales beharrten gegenüber der Abtei allerdings darauf, dass alles, was die Judeca hinzugewinne, an die kaiserliche Kammer abzuführen sei, weshalb die Mönche auch noch an Papst Gregor IX. apellierten. ${ }^{97}$

Der Vorwurf de Iudecis ablatis quibusdam ecclesiis, den Gregor IX. 1236 dem Kaiser in einer series Gravaminum der sizilischen Kirchen machte, bezieht sich also höchstwahrscheinlich auf die Folgen der nova statuta für die Färbereien. ${ }^{98}$ Und es war dieser Vorwurf, auf den hin Friedrich II. die grundsätzliche Un-

92 Eduard Winkelmann (Hsg.): Acta Imperii inedita seculi XIII. Urkunden und Briefe zur Geschichte des Kaiserreichs und des Königreichs Sicilien in den Jahren 1198 bis 1273. Innsbruck 1880, Nr. 796.

93 Dieter Girgensohn/Norbert Kamp, Urkunden und Inquisitionen der Stauferzeit aus Tarent, in: QFIAB 41, 1961, S. 137-234, hier S. 152.

94 Kамp, Vom Kämmerer zum Sekreten (wie Anm. 91), S. 57.

95 Girgensohn/Kamp, Urkunden und Inquisitionen (wie Anm. 93), Nr. IX.

96 Richardus de Sancto Germano, Chronica, ed. Carlo Alberto Garufi (RIS 7/2), Bologna 1938, S. 176: Tintorias omnes de regno ad opus fisci imperialis recipi precipit imperator, et super hoc suas mittit litteras generales. Quas cum duo Iudei pro iudeca Sancti Germani recipienda detulerint, ipsam Reginus archiepiscopus capi prohibuit mandans ipsis judeis, ut ipsam in pace dimittant monasterio Casinensi.

97 Simonsohn, The Apostolic See and the Jews (wie Anm. 9) 1, Nr. 131.

98 Shlomo Simonsonn: The Jews of Sicily. Vol 1: 383-1300 (Studia Post-Biblica, Vol. 48,3.) Leiden/New York/Köln 1997, Nr. 212. 
terordnung der Juden unter die Monarchie beanspruchte: Die Juden seien ihm tam in imperio quam in regno nach gemeinem Recht direkt unterworfen. Dennoch habe er sie keiner Kirche entfremdet, die bezüglich ihrer ein ius speciale vorgebracht hätte. ${ }^{99}$

Ebenfalls 1236 erscheint erstmals die berühmte Bezeichnung der Juden als servi camere nostre, im Privileg Friedrichs II. für die Juden des Reichs nördlich der Alpen vom Juli des Jahres. ${ }^{100}$ Im November 1237 erscheint der Begriff dann erstmals im Königreich Sizilien. ${ }^{101}$ Diese sogannnte ,Kammerknechtschaft', so hat unlängst Alexander Patschovsky zeigen können, bezeichnete im Kern eben jene allgemeine, direkte Unterstellung der Juden unter den Kaiser bzw. König, auf der Friedrich II. zunächst gegenüber den sizilischen Kirchen und dann gegenüber Papst Gregor IX. beharrt hatte. ${ }^{102}$ Es spricht daher alles dafür, dass man das Konzept der Kammerknechtschaft am Hof Friedrichs II. entwickelt hatte, um die Ansprüche des Königs an den Juden in der Konkurrenz mit den lokalen kirchlichen Gewalten zu behaupten, in der sie im Königreich Sizilien standen.

Die gleiche unmittelbare Unterordnung der Juden, die Friedrich II. zufolge communi iure bestünde, beanspruchten nach ihrem Herrschaftsantritt in Süditalien auch die Anjou für sich und den königlichen Fiskus. In ihren Mandaten werden Juden wiederholt als servi camere regie bzw. als servi nostri bezeichnet. ${ }^{103}$ Und wie Friedrich II. zeigt sich zumindest auch Karl I. vielfach bestrebt, die königliche Prärogative in bezug auf die Juden gegenüber den konkurrierenden Interessen der Kirchen zu bewahren. Hierbei geht es widerum um die Einkünfte aus der Färberei.

Im Dezember 1273 ließ Karl I. dem Erzbischof von Trani durch den Justitiar der Terra di Bari untersagen, von den dortigen Juden mehr als 37 2/3

99 Jean-Louis-Alphonse Huillard-Bréholles: Historia diplomatica Friderici secundi 4/ 2, Paris 1855, S. 912: Judeos autem, etsi tam in imperio quam in regno nobis communi iure immediate subiaceant, a nulla tamen ecclesia illos abstulimus que super eis ius speciale pretenderet, quod communi iure nostro merito preferretur.

100 MGH Constitutiones et Acta Publica, Bd. 2, ed. Ludwig Weiland. Hannover 1896, Nr. 204.

101 Simonsohn, Jews of Sicily 1 (wie Anm. 98), Nr. 214.

102 Patschovsкy, Das Rechtsverhältnis der Juden zum deutschen König (wie Anm. 84), S. 364; vgl. Dietmar Willoweit: Vom Königsschutz zur Kammerknechtschaft. Anmerkungen zum Rechtsstatus der Juden im Hochmittelalter, in: Karlheinz Müller/ Klaus WitTstadt (Hrsg.): Geschichte und Kultur des Judentums. (Quellen und Forschungen zur Geschichte des Bistums und Hochstifts Würzburg, Bd. 38.) Würzburg 1988, S. 71-89; hier S. 82 f.; Abulafia, Servitude of Jews and Muslims (wie Anm. 84), S. $47 \mathrm{f}$.

103 Del Giudice, Codice Diplomatico 1 (wie Anm. 38), Nr. 116, Anm. 1.; Houben, Neue Quellen zur Geschichte der Juden und Sarazenen (wie Anm. 20), Nr. 2 , 7; RCA (wie Anm. 21) 32, S. $66 \mathrm{f}$. 
Unzen im Jahr zu fordern und sie anderweitig zu belästigen, obwohl ,sie jährlich nur soviel und nicht mehr als Abgabe zu zahlen verpflichtet sind, so wie es im Privileg des Kaisers Heinrich, seligen Angedenkens und Königs von Sizilien ... überdeutlich enthalten ist ${ }^{1}{ }^{104}$ Und nicht nur in diesem, denn auch Friedrich II. hatte in seinem berühmten Privileg für die Juden von Trani 1221 diese Summe festgeschrieben. ${ }^{105}$ Die Mittel, derer sich die Bischofskirche dabei bediente waren drastisch. Zum einen legten sie den Juden von Trani Zwangsanleihen (mutua) auf, durch die sie ihnen beträchtliche Summen abpressten. Zum anderen nutzten sie die Unterstellung der Juden unter das Gericht des Erzbischofs aus, erhoben unbegründete Klagen gegen sie und kerkerten sie solange ein, bis sie sich durch Zahlungen aus dieser Lage befreiten. ${ }^{106}$

Der Konflikt zwischen Königtum und Prälaten um die Juden, den die Neuorganisation der Färbereien durch Friedrich II. verursacht hatte, setzte sich also auch nach dem Ende der Staufer fort. Nicht zuletzt die Juden von Trani hatten von den Wirtschaftsreformen Friedrichs II. erheblich profitiert. Wurde in ihren Händen doch nicht nur die Seidenfärberei, sondern auch der Handel mit Seide monopolisiert, und zwar für das gesamte Reich. ${ }^{107} \mathrm{Im}$ Jahr 1284 wurden die Steuereinnahmen aus der Färberei für 130 Unzen verpachtet. ${ }^{108}$ Also für mehr als das zehnfache dessen, was die Färberei in Tarent einbrachte. Angesichts dessen wollte sich der Traneser Metropolit nicht mit den fixen Einkünften begnügen, wie sie Heinrich VI. und Friedrich II. festgeschrieben hatten, und hatte sich 1267 von Papst Clemens IV. neben anderen Rechten und Einkünften auch die Judengemeinde von Trani cum omni iure suo bestätigen lassen. ${ }^{109} \mathrm{Er}$ beanspruchte also weiterhin die gesamten Einnahmen aus den direkten wie den indirekten Judensteuern für sich. Und um dieses Ziel zu erreichen, waren ihm offensichtlich einige Mittel recht.

Dass er dabei nicht der einzige war, dafür sprechen weitere Mandate Karls I. aus den siebziger Jahren des 13. Jahrhunderts, etwa für das insulare Agrigento oder für das festländische Bari. In letzterem hatten die Juden bereits einige Monate vor ihren Glaubensbrüdern aus dem benachbarten Trani Klage über ihren Erzbischof geführt. Auch dieser verlangte von ihnen Abgaben, die über die festgeschriebene Summe hinausgingen. Diese bestand aus vier Unzen Gold, zwei

104 Del Giudice, Codice Diplomatico 1 (wie Anm. 38), Nr. 116, Anm. 1: ... tantum et non amplius annis singulis nomine date solvere teneantur prout in privilegio clare memorie herrici Romanorum Imperatoris, et Regis Sicilie predecessoris nostri plenius dicitur contineri.

105 Winkelmann (Hsg.), Acta Imperii inedita (wie Anm. 92), Nr. 221.

106 Del Giudice, Codice Diplomatico 1 (wie Anm. 38), Nr. 116, Anm. 1.

107 Winkelmann (Hsg.), Acta Imperii inedita (wie Anm. 92), Nr. 785.

108 Pietro Egidi: La Colonia Saracena di Lucera e la sua distruzione. Napoli 1912, S. 122 f., Anm. 6.

109 Giovanni Battista Beltrani: Cesare Lambertini é la Societá Familiare in Puglia durante i Secoli XV e XVI. Bd. 1. Milano/Napoli/Pisa 1884., Nr. 1. 
Pfund Pfeffer und einer Unze Seide zu Weihnachten sowie zwei Pfund Pfeffer und einer Unze Seide zu Ostern. Stattdessen verlangte der Bareser Oberhirte nun 20 Unzen Gold jährlich. ${ }^{110}$ Dass Seide bei den ursprünglichen Abgaben der Juden an den Bischof eine so große Rolle spielte, zeigt abermals, welche Bedeutung die Einkünfte der Färberei hatten.

Auch nach dem Dynastiewechsel zu den Anjou bestand der Konflikt zwischen Königtum und Kirchen um die politische Stellung der Juden und das heißt vor allem um deren Steuern also fort. Wie Friedrich II. versuchte auch Karl I., die Rechte der Kirchen an den Juden zu beschränken bzw. zu verhindern, dass sie die Juden über Grenzen, die ihnen das Königtum zu setzen versucht hatte, hinaus beanspruchten. Und wie der Staufer setzen die Anjou den Ansprüchen der Kirchen das Konzept einer unmittelbaren Unterordnung der Juden unter die Monarchie entgegen, indem sie die Juden als servi camere regie beanspruchten.

Es war dieser Konflikt, der den sozialen Kontext für die inquisitorische Judenverfolgung im Königreich Neapel bildete. Und der Effekt den sie hatte, lässt sich ohne ihn nicht erklären. Aufgrund der politischen Stellung der Juden im mittelalterlichen Süditalien, die zwischen Königtum und Kirchen umstritten war, hatte der König hier nämlich wesentlich weniger Anlass, den Inquisitoren Widerstand entgegenzusetzen und so die inquisitorische Judenverfolgung zu bremsen, als etwa die Könige von Aragon und Frankreich und der Graf der Provence. Denn anders als dort war hier die Gerichtsgewalt des Königtums über die Judengemeinden davon nicht betroffen, befand diese sich doch in der Regel in den Händen der Kirchen. Das gleiche gilt für die Einkünfte aus den direkten und indirekten Judensteuern. Die königliche Kammer erlitt durch die Verfolgung der Juden durch die Inquisitoren also auch keine finanziellen Einbußen. ${ }^{111}$ Im Gegenteil: Die Verfolgung der Juden durch die Inquisitoren erschloss dem königlichen Fiskus sogar neue Einkünfte. Denn zwei Drittel der Einnahmen, die die Inquisitoren aus Geldbußen und den Vermögenskonfiskationen erzielten, zu denen sie die Juden verurteilten, gingen ja an die königliche Kammer.

Vor allem unter Karl II. werden diese Einkünfte nicht gänzlich unerwünscht gewesen sein. Befand sich sich die Krone infolge der Sizilischen Vesper doch in einer höchst prekären finanziellen Situation. Denn durch diese brachen zum einen die enormen Einkünfte weg, die dem Königtum seit jeher aus der Insel zugeflossen waren. Hinzu traten die Schäden aus dem Krieg der Vesper, der bis 1296 fast ausschließlich auf dem Festland stattfand und Kalabrien und große Teile der Basilikata und des Prinzipats verwüstete. Die direkten Steuereinnahmen brachen infolge dessen ein. Dafür wuchsen die Militärausgaben so stark, dass der Krieg der sizilischen Vesper „die finanziellen Ressourcen des Regno

110 Del Giudice, Codice Diplomatico 1 (wie Anm. 38), Nr. 116.

111 So Starr, Mass Conversions (wie Anm. 11), S. 205, $208 \mathrm{f}$. 
völlig aufzehrte“. ${ }^{112}$ Im Jahr 1292 bemerkte der König selbst, dass maior sit exitus quam introitus pecunie. ${ }^{113}$

Die Verfolgung und die Bekehrung der Juden durch die Inquisitoren brachte der königlichen Kammer jedoch nicht nur einmalige Sondereinnahmen. Die Steuerbefreiungsprivilegien für die konvertierten Juden von 1294 bringen nämlich klar zum Ausdruck, dass nur die erste Generation der Konvertiten auf Lebzeiten von allen Abgaben befreit sein sollte. ${ }^{114}$ Ihre Nachkommen sollten dann die gleichen Steuern zahlen, wie die anderen Christen auch, wenn man so will also in jene unmittelbare Beziehung zur königlichen Kammer treten, die zwischen ihren Vorfahren und dem Königtum gegen den Widerstand der Kirchen nie hatte etabliert werden können. Nur waren die Nachkommen der Juden, die die staufischen und angiovinischen Könige als unmittelbar ihnen unterworfen beansprucht hatten, keine Juden mehr.

Das alles soll nicht heißen, dass die Inquisitoren gleichsam Instrumente der fiskalischen Interessen des Königtums waren. Das Handeln der Inquisitoren folgte seiner eigenen Logik. Dies wird nicht zuletzt daran deutlich, dass die Inquisition in dieser Zeit nicht nur in Süditalien, sondern auch in anderen Reichen des Mittelmeerraums versuchte, die Juden auf der Basis von turbato corde zu verfolgen, wo sie freilich immer wieder auf den Widerstand der weltlichen Autorität stießen. Im Königreich Neapel dagegen konnte es zu einer kumulativen Radikalisierung der ungebremsten inquisitorischen Judenverfolgung kommen, weil ihr die Interessen des Königtums hier nicht zuwiderliefen, sondern, im Gegenteil, in Wahlverwandtschaft zu ihr standen und die Monarchie deshalb auf die Initiative der Inquisitoren anders reagierte. Die Inquisitoren konnten die Verfolgung einzelner Juden, die unter dem Verdacht des relapsus standen bzw. dazu Beihilfe geleistet zu haben, auf die systematische Verfolgung ganzer Gemeinden als fautores et receptatores hereticorum ausweiten und hieraus die Druckmittel gewinnen, mit denen sie einen Gutteil der Judengemeinden des regno 1292 zum Übertritt zum Christentum brachten. Denn dies korrespondierte mit Bestrebungen der Monarchie, die Juden ausschließlich der königlichen Kammer dienstbar zu machen; Bestrebungen, die jedoch stets auf den Widerstand der Kirchen gestoßen waren und seit Friedrich II. zu einem massiven Konflikt zwischen den Kirchen des Reichs und dem Königtum geführt hatten.

Es wäre überzeichnet, die Begünstigung der inquisitorischen Judenverfolgung und -bekehrung als Fortsetzung der staufischen Politik mit anderen Mitteln zu bezeichnen. Vor allem hieße es, die Perspektive der Juden gänzlich

112 Kiesewetter, Anfänge der Regierung Karls II. (wie Anm. 7), S. 489.

113 RCA (wie Anm. 21) 40, S. 31; Kiesewetter, Anfänge der Regierung Karls II. (wie Anm. 7), S. 490.

114 S.o. Anm. 27. 
auszublenden. Denn für sie bedeutete der Übergang von den Staufern zu den Anjou den Beginn einer Zeit der Verfolgung und Zerstörung ihrer Gemeinden. Blendet man jedoch die Kontinuität aus, die zum einen zwischen den Bestrebungen Friedrichs II. und denen der ersten Anjou bestand, die Juden dem königlichen Fiskus dienstbar zu machen, und blendet man zum anderen die Kontinuität des strukturellen Konflikts zu den Interessen der Kirchen aus, in dem diese Bestrebungen standen, dann bleibt schlichtweg unverständlich, wie die convivencia von Christen und Juden, für die das mittelalterliche Sizilien neben der iberischen Halbinsel nicht zu unrecht das Paradebeispiel darstellt, von einer Dynastie zur anderen in eine schwere Krise geraten konnte.

Die strukturelle Konfliktlage, die die Massenkonversion von 1292 möglich gemacht hatte, setze sich sogar über diese hinaus fort, und dies hatte für die Situation der konvertierten Juden und ihrer Nachkommen weitreichende Folgen, die hier allerdings nur noch angedeutet werden können. Denn vielerorts setzten die Kirchen den Maßnahmen von Königtum und Inquisitoren erfolgreich Widerstand entgegegen. Mit dem Resultat, dass die Nachkommen der Konvertiten von 1292 in der einen oder anderen Weise wieder in die Gewalt der Kirchen gerieten.

Die Neofiti der südapulischen Terra d'Otranto etwa wanderten nach Kalabrien aus und gründeten mit den dortigen Juden, die nie konvertiert waren, wie es eine Urkunde von 1366 nennt: novas iudaicas, lebten also wieder als Juden. ${ }^{115}$ Und 1403 wies Papst Bonifaz IX. Bischöfe und Erzbischöfe in Kalabrien und der Terra d'Otranto auf Bitten der dortigen Juden an, dafür zu sorgen, dass diese nicht mehr von den Inquisitoren behelligt würden, sondern ausschließlich dem bischöflichen Gericht unterstünden. ${ }^{116}$

In Bari ist für das frühe 14. Jahrhundert eine ganze Reihe von Fällen belegt, in denen konvertierte Juden sich, ihre Familien und ihr Vermögen dem Zugriff der Inquisition entziehen, indem sie sich der Abtei S. Nicola tradieren. ${ }^{117}$

Die erzbischöfliche Kirche von Trani schließlich erreichte 1328, dass Papst Johannes XXII. den Inquisitoren in partibus Apuliae untersagte, ohne ihre Zustimmung gegen die Juden oder Neofiti der Stadt Trani vorzugehen. Denn die Inquisitoren hätten den Juden, die an die erzbischöfliche Mensa einst ampla emolumenta abgeführt hätten, solche gravamina zugefügt, dass nur noch wenige übrig geblieben, die außerdem noch in solche Armut herabgedrückt worden seien, dass die genannte Mensa von ihnen nur noch sehr wenig profitiere, und

115 Codice Diplomatico Brindisino. Vol. 2: Periodo Angioino (1304-1397), ed. Michaela Pastore Doria. Bari 1964, Nr. 94.

116 Simonsohn, The Apostolic See and the Jews (wie Anm. 9) 1, Nr. 502.

117 CDB (wie Anm. 31) 13, Nr. 103; 116; 124, 127, 128; Le pergamene di San Nicola di Bari: Periodo Angioino (1309-1343), ed. Francesco Nitti de Vito (CDB [wie Anm. 31] 16). Trani 1941, Nr. 11: Gerardo Cioffari: Storia dei Dominicani in Puglia (1221-1350). Bari 1986, S. 69-72; Nr. 25. 
sie würden nun die Neofiti in gleicher Weise bedrücken, plus ab eis temporalia lucra querentes quam aliquam edificationem facere spiritualem. ${ }^{118}$

Die erwähnten ampla emulomenta hatte die Kirche von Trani allerdings nicht nur einstmals von den dortigen Juden bezogen, sondern wollte sie auch weiter beziehen, nachdem diese konvertiert waren. Der König hatte dem Erzbischof von Trani deshalb 1305 und 1307 untersagen müssen, die ehemaligen Juden ihrer Konversion zum Trotz weiterhin vor sein Gericht zu ziehen und von ihnen jene Abgaben zu verlangen, die ihm einstmals die Juden geschuldet hatten. ${ }^{119}$ Diese Anweisungen waren jedoch wirkungslos, denn auch siebzig Jahre später forderte der Metropolit von den Neofiti Steuern und zwang sie vor sein kirchliches Gericht. ${ }^{120}$ Und noch 1422 betonte der Erzbischof von Trani, seine Kirche habe seit jeher die Gerichtsbarkeit ausgeübt supra omnes es singulos neophidos Tranensis civitatis tamque ecclesie homines. ${ }^{121}$

Dass die Inquistoren im Jahr 1292 einen Großteil der apulischen und kampanischen Juden konvertieren konnten, wurde wesentlich begünstigt durch den Konflikt zwischen den Kirchen und der Monarchie, der die politische Stellung der Juden im Königreich Sizilien bzw. Neapel im 13. Jahrhundert bestimmte. Denn hieraus resultierte eine spezifische Wahlverwandtschaft zwischen den Bestrebungen der Inquisition, Juden zu verfolgen, die sie der Beihilfe zur Apostasie verdächtigten und diese dann zu bekehren, und denen des Königtums, die Juden aus der Herrschaft der Kirchen herauszulösen und ausschließlich der königlichen Kammer dienstbar zu machen. Auch die Massenkonversion der Juden des Königreichs Neapel im Jahr 1292 hat ihren Ort also im Rahmen von Prozessen der Herrschaftszentralisierung. ${ }^{122}$ Allerdings gelang es den Kirchen mancherorts, die konvertierten Juden und ihre Nachkommen wieder ihrer Herrschaft zu unterstellen. Im Bannkreis der lokalen Gewalten exitierte die spezifisch süditalienische convivencia, nun als Mit-, Neben-, und Gegeneinander von Juden, Christen und Neofiti noch einmal gut 200 Jahre weiter, bis die neue Einheitsmonarchie des katholischen Königs Ferdinand II. von Aragon ihr zu Beginn des 16. Jahrhunderts endgültig das Ende bereitete. ${ }^{123}$

118 Simonsohn, Apostolic See and the Jews (wie Anm. 9) 1, Nr. 336.

119 Caggese, Roberto d'Angio 1 (wie Anm. 26), S. 90 f.

120 Beltrani, Cesare Lambertini (wie Anm. 109), Nr. 35.

121 Beltrani, Cesare Lambertini (wie Anm. 109), Nr. $78 \mathrm{f}$.

122 Vgl. Sophia Menache: The king, the Church and the Jews: some considerations on the expulsions from England and France, in: Journal of Medieval History 13, 1987, S. $223-$ 236.

123 Viviana Bonazzoli: Gli Ebrei del regno di Napoli all'epoca della loro espulsione. II parte: Il periodo spagnolo (1501-1541), in: Archivio Storico Italiano 138, 1981, S. 179-287. 
